\title{
INFLUÊNCIA DO VÁCUO, FOTOPERÍODO E SUBSTRATO NA SELEÇÃO DE CANA-DE-AÇÚCAR RESISTENTE A Ustilago soitaminea
}

\section{AMARILES SANTOS DIAS \\ Engenheira Agrônoma}

Orientador: Prof. Dr. HASIME TOKESHI

Tese apresentada à Escola Superior de Agricultura "Luiz de Queiroz", da Universidade de São Paulo, para obtenção do título de Doutor em Agronomia. Área de Concentração: Fitopatologia.

PIRACICABA

Estado de São Paulo - Brasil

Abril, 1981 


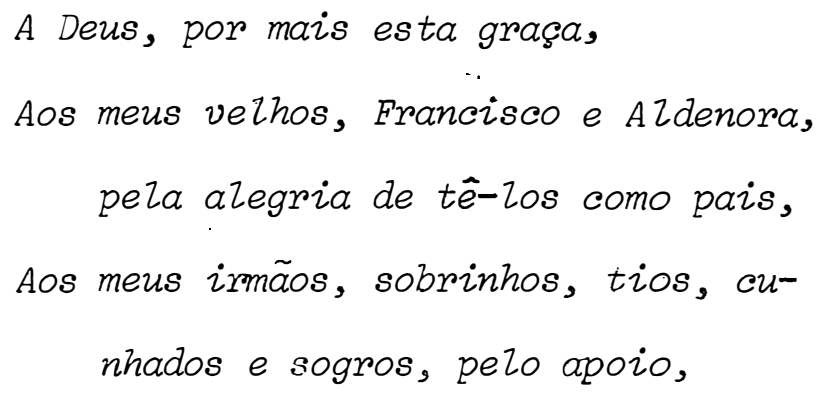

Ao José Fernando, companheiro

de todas as horas, pela graça

de tề-lo como esposo,

OFEREÇO. 


\section{AGRADEC IMENTOS}

Ao Professor Hasime Tokeshi, pelo exemplo de orientação, ensinamen tos e versão do resumo para o inglês; a ele, esposa e filhos, pe la amizade.

A Empresa Maranhense de Pesquisa Agropecuária e Secretaria de Agri cultura do Maranhão, pela oportunidade de aperfeiçoamento.

Ao meu marido José Fernando Soares Dias, pela dedicação e análises estatísticas.

Aos irmãos Itaan Santos da Fonseca, Vilma S,antos da Fonseca, Gilson Mendes Caminha e Maria do Socorro Dias Caminha, pelo inesgotável apoio dispensado.

Aos Professores Francisco Ferraz de Toledo, José Dias Costa e Ferdinando Galli, pelas considerações dispensadas.

Ao Professor Hiroshi Kimati, pelos ensinamentos e revisão do original.

Aos Professores do Departamento de Fitopatologia da ESALQ, pelos valiosos ensinamentos.

A Coordenadoria do Aperfeiçoamento de Pessoal de Nível Superior, Es cola Superior de Agricultura "Luiz de Queiroz" e Programa Nacional de Melhoramento da Cana-de-Açúcar, pelas facilidades concedi das na realização deste trabalho.

Aos amigos Mauro Sérgio Tenente, Renata Cesar Vilardi Tenente e Modesto Barreto, pelo excelente convívio mantido durante o Curso. 
iv.

Aos funcionários Pedro Silva, Luiz Carlos Veríssimo e Antonio Vitti, pela colaboração e amizade.

A Maria Izalina Ferreira Alves e família, e funcionários do Depar tamento de Fitopatologia e Seção de Pós-Graduação da ESALQ, pelas atenções dispensadas.

Aos colegas do Curso de Pós-Graduação, pela troca de idéias. 


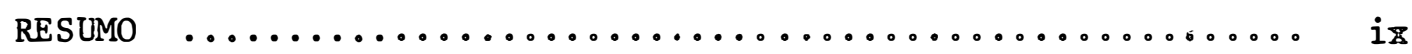

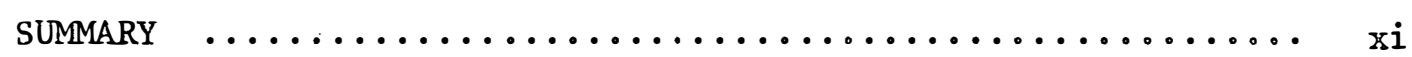

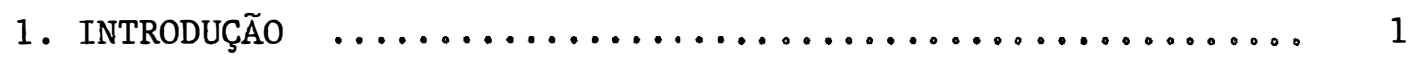

2. REVISÃo DE LiteratuRA $\ldots \ldots \ldots \ldots \ldots \ldots \ldots \ldots \ldots \ldots \ldots \ldots \ldots$

2.1 - Método de Inoculação em Cariopses com U. scitominea 3

2.1.1 - Uso do vácuo na inoculação com U. scitaminea 5

2.2 - Influência de Microrganismos na Germinação e Desenvolvimento de Plântulas de Cana-dé-Açúcar ....... 6

2.3 - Influência do Substrato na Germinação e Desenvolvimento de Plântulas de Cana-de-Açúcar $\ldots \ldots \ldots \ldots . . . .8$

3. MATERIAL E MÉTODOS $\ldots \ldots \ldots \ldots \ldots \ldots \ldots \ldots \ldots \ldots \ldots \ldots \ldots . \ldots \ldots$

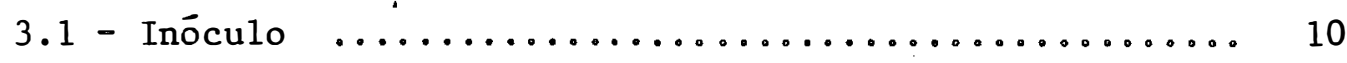

3.1.1 - Obtenção, armazenamento e teste de germinação 10

3.1 .2 - Determinação qualitativa dos fungos contaminantes dos esporos de U. scitcominea ...... 11

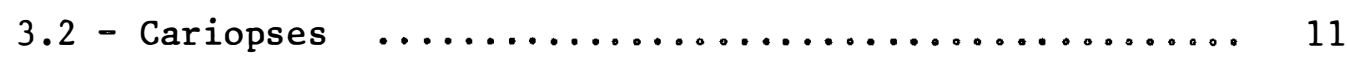

3.2 .1 - Origem, beneficiamento e armazenamento .... 11

3.2 .2 - Teste de germinação $\ldots \ldots \ldots \ldots \ldots \ldots \ldots \ldots \ldots \ldots$

3.2.3 - Determinação quantitativa dos fungos contaminantes ...................... 13

3.2.3.1 - Testes de patogenicidade com Colletotrichum falcatum ......... 13 
vi.

Pāg。

3.3 - Influência do Vácuo na Germinação de Cariopses .... 15

3.4 - Influência do Vácuo na Colonização de Plântulas por

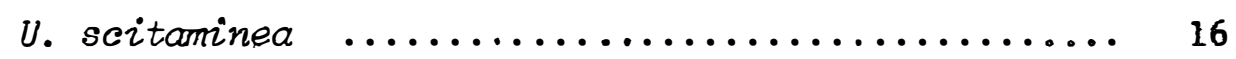

3.5 - Comparação de Métodos de Inoculação na Colonização de Plântulas por U. scitaminea ............... 17

3.6 - Influência da Cultivar e Inoculação com U.scitcominea na Mortalidade de Plântulas $\ldots \ldots \ldots \ldots \ldots \ldots \ldots . . . . . . .18$

3.7 - Relação entre a Presença de Micéli,o de U. scitominea nas Folhas e o Aparecimento de Chicotes ......... 19

3.8 - Influência do Fotoperíodo na Colonização de Plântulas por U. scitominea e na Mortalidade de Plântulas ... 20

3.9 - Influência do Substrato e Inoculação com U. scitaminea na Germinação de Cariopses, Colonização e Mortalidade de Plântulas $\ldots \ldots \ldots \ldots \ldots \ldots \ldots \ldots \ldots \ldots$

3.9.1 - Influência do substrato e inoculação na ger-

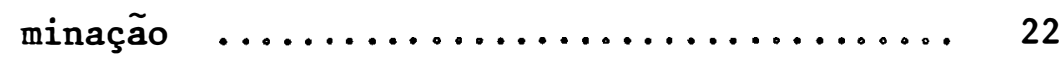

3.9 .2 - Influência do substrato na colonização $\ldots . .22$

3.9 .3 - Influência do substrato e inoculação na mortalidade $\ldots \ldots \ldots \ldots \ldots \ldots \ldots \ldots \ldots . \ldots . \ldots 23$

3.9 .4 - Delineamento experimental $\ldots \ldots \ldots \ldots \ldots \ldots 23$

3.10 - Fungos Encontrados nas Plântulas Mortas ........ 23

3.11 - Anālise Estatística dos Dados ............... 24

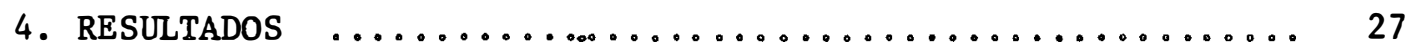

4.1 - Determinação Quantitativa dos Fungos Contaminantes de

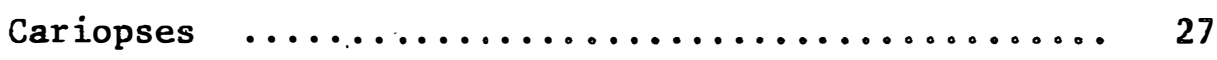


vii。

Pág.

4.1 .1 - Testes de patogenicidade com C. falcatum .. 27

4.2 - Influência do Vácuo na Germinação de Cariopses .... 29

4.3 - Influência do Vácuo na Colonização de Plântulas por

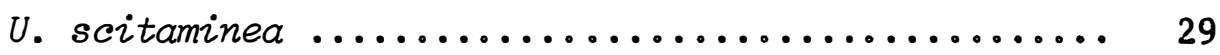

4.4 - Comparação de Métodos de Inoculação na Colonização de Plântulas por $U$. scitconinea ................ 30

4.5 - Influência da Cultivàr e Inoculação com U.scitconinea na Mortalidade de Plântulas ................ 31

4.6 - Relação entre a Presença de Micélio de U. scitaminea nas Folhas e o Aparecimento de Chicotes ........ 32

4.7 - Influência do Fotoperíodo na Colonização de Plântulas por U. scitaminea e na Mortalidade de Plântulas ... 36

4.8 - Influência do Substrato e Inoculação com U. scitcominea na Germinação de Cariopses, Colonização e Morta-

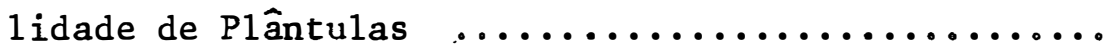

4.8.1 - Influência do substrato e inoculação na ger-

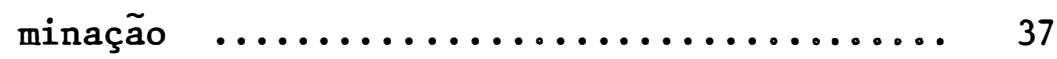

4.8 .2 - Influência do substrato na colonização $\ldots . .38$

4.8.3 - Influência do substrato e inoculação na mor-

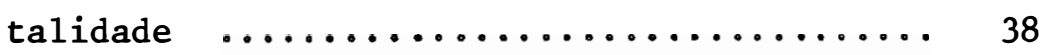

4.9 - Fungos Encontrados nas Plântulas Mortas ....... 39

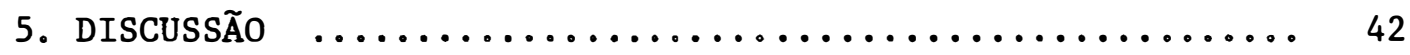

5.1 - Determinação Quantitativa dos Fungos Contaminantes de

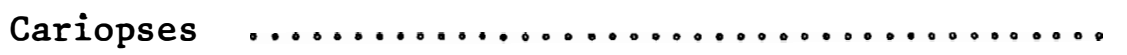


viii.

Pāg.

5.1 .1 - Testes de patogenicidade com C. falcatron .. 43

5.2 - Influência do Vảcuo na Germinação de Cariopses. ... 43

5.3 - Influência do Vảcuo na Colonização de Plântulas por U. scitaminea ........................... 44

5.4 - Comparação de Métodos de Inoculação na Colonização de Plântulas por U. scitaminea ................. 44

5.5 - Influência da Cultivar e Inoculação com U.scitaminea na Mortalidade de Plântulas ................ 45

5.6 - Relação entre a Presença de Micélio de U. scitaminea nas Folhas e o Aparecimento de Chicotes ......... 46

5.7 - Influência do Fotoperiodo na Colonização de Plântulas por U. scitaminea e na Mortalidade de Plântulas ... 48

5.8 - Influência do Substrato e Inoculação com U. scitaminea na Germinação de Cariopses, Colonização e Mortalidade de Plântulas ...................... 50

5.8.1 - Influência do substrato e inoculação na ger-

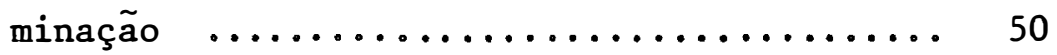

5.8 .2 - Influência do substrato na colonização .... 52

5.8.3 - Influência do substrato e inoculação na mortalidade $\ldots \ldots \ldots \ldots \ldots \ldots \ldots \ldots \ldots \ldots \ldots$

5.9 - Fungos Encontrados nas P1ântulas Mortas ........ 54

6. CONCLUSÕES $\ldots \ldots \ldots \ldots \ldots \ldots \ldots \ldots \ldots \ldots \ldots \ldots \ldots \ldots \ldots \ldots$

7. LITERATURA CITADA $\ldots \ldots \ldots \ldots \ldots \ldots \ldots \ldots \ldots \ldots \ldots \ldots \ldots \ldots$ 
ix .

INFLUENCIA DO VACUO, FOTOPERIODO E SUBSTRATO NA SELEÇÃO DE CANA-DE-AÇDCAR RESISTENTE A Ustilago scitaminea

$\begin{array}{ll}\text { Autor: } & \text { Amariles Santos Dias } \\ \text { Orientador: } & \text { Dr. Hasime Tokeshi }\end{array}$

RESUMO

A influência de contaminantes de cariopses de cana-de-açücar, vácuo, fotoperíodo e substrato foi analisada quanto à germinação, mortalidade de plântulas inoculadas com $U$. scitaminea e relação entre a presença de micélio nas folhas e a produção de chicotes.

0 fungo Colletotrichum falcatum foi encontrado pela primeira vez em cariopses de cana-de-açúcar.

As cariopses, das cultivares IAC $48 / 65$, CO 419 e NA 56-79, foram inoculadas com U. scitconinea $\left(6 \times 10^{6}\right.$ esporos $\left./ \mathrm{ml}\right)$. A aplicação do vãcuo na inoculação prejudica a germinação e tende a aumentar a eficiência de seleção. O fotoperíodo não interfere na mor talidade de plântulas inoculadas com U. scitcominea.

o substrato vermiculita é superior ao ágar-água por 
aumentar a germinação e eficiência de seleção, e não interferir na mortalidade de plântulas.

A causa mais importante de morte de plântulas é a pre sença de microrganismos patogênicos nas cariopses.

Plantas nas quais é detectado micélio de U. scitaminea nas folhas tendem a produzir chicotes precocemente e são mais suscetiveis do que aquelas nas quais isto não ocorre. 
Adviser: $\quad$ Dr. Hasime Tokeshi

SUMMARY

The influence of sugarcane caryopses contaminants, va cuum, photoperiod and substratum were analysed in relation to their actions on germination, mortality of inoculated seedlings with $U$. scitominea and relation of smut mycelium in the leaves and whips development.

The fungi Colletotrichum falcatum was found for the first time in sugarcane caryopses.

Sugarcane caryopses from cultivars IAC 48/65, CO 419 and NA 56-79 were inoculated with $U$. scitaminea $\left(6 \times 10^{6}\right.$ spores/ml). The vacuum application during the inoculation process decreased the germination with tendency to increase the selection efficiency. The photoperiod did not interfere in mortality of seedlings inoculated with $U$. scitaminea. 
xii.

Vermiculite is substratum turned out to be better than water-agar to enhance the germination and selection efficiency, but did not interfere in seedlings mortality.

The main cause of seedlings death is the presence of pathogenic microorganisms in the caryopses.

Plants in which mycelium of $U$. scitominea was detected tend to produce whips precociously and are more susceptible than those where mycelium was not observed. 
1. INTRODUÇÃO

o carvão da cana-de-açúcar, causado pelo fungo UstiZago scitaminea Syd., è considerado de grande importância econômica para o Brasil (CARVALHO, 1949 e BRIEGER, 1965). Esta opinião atua1mente é mais acentuada, umạ vez que a cultura da cana-de-açúcar ocu pa lugar de destaque na política brasileira de álcool-combustível.

Por ser o plantio de cultivares resistentes a medida mais racional e econômica no controle do carvão da cana-de-açúcar (ANTOINE, 1961 e TOKESHI, 1980), a obtenção dessas cultivares è um dos requisitos dos programas de melhoramento dessa cultura. No atual programa de melhoramento da cana-de-açúcar, os clones são submetidos aos testes preliminares de carvão após a seleção a outras carac terísticas agronômicas e tecnológicas, cuja duração mínima é de qua tro anos. Decorrido esse período de seleção, o número de clones dis 
poníveis aos testes preliminares de carvão é limitado, o que contrí bui para elevar o custo desse material (TOKESHI, 1979).

Face às considerações sobre o atual programa de me1horamento da cana-de-açúcar, o Departamento de Fitopatologia, da Escola Superior de Agricultura "Luiz de Queiroz" - ESALQ, sentiu a necessidade de desenvolver um método mais precoce e eficiente de se leção de plântulas resistentes a $U$. scitaminea. Assim, trabalhos ef $\underline{\text { e }}$ tuados por MATA (1975), MATA e TOKESHI (1976), SANGUINO (1976), DUAR TE (1976), DUARTE e TOKESHI (1978, 1978a), BLEICHER (1978), SILVA (1978), SANGUINO e TOKESHI (1980), BLEICHER. e TOKESHI (1980, 1980a) e SILVA e TOKESHI (1980) foram conduzidos nesse Departamento, buscando informações sobre os possíveis fatores que poderiam ter infiluência nesse método.

Considérando-se que o método de seleção de plântulas reśistentes a $U$. scitcominea é relativamente novo, alguns pontos ine rentes a ele ainda são carentes de informações. Assim, visando fornecer-1he subsídios, o presente trabalho foi conduzido principalmen te para verificar a influência do vácuo, fotoperíodo e substrato na germinação de cariopses, colonização de plântulas por U. scitaminea e mortalidade de plântulas após o transplante. 


\section{REVISAO DE LITERATURA}

2.1 - Método de Inoculação em Cariopses com U. scitaminea

o plantio de cultivares resistentes é a medida mais racional e econômica para controlar o carvão da cana-de-açúcar (ANTOINE, 1961 e TOKESHI, 1980). Sendo assim, a seleção para resistência ao carvão é um dos requisitos dos programas de melhoramento.

Vários métodos de inoculação em gemas de cana-de-açū car, adotados em diversas partes do mundo, foram revisados por LEE-LOVICK (1978) e FERREIRA et alii (1980).

0 primeiro relato de carvão em plântulas de cana-de-açúcar foi feito por TALBALLA (1969). Ao examinar flexas, para verificar a viabilidade do grão de pólen, observou a presença de numerosos teliosporos de $U$. sicitominea. Cariopses dessas flexas foram 
semeadas em solo esterilizado e deram origem a plântulas que produziram chicotes, dez semanas após a semeadura.

A inoculação, em cariopses e plântulas de cana-de-açúcar, com U. scitaminea foi realizada por TALBALLA e NASR (1974), DUARTE (1976), BLEICHER (1978), DUARTE e TOKESHI (1978), SILVA (1978), BLEICHER e TOKESHI (1980) e SILVA e TOKESHI (1980).

0 método de inoculação em cariopses de cana-de-açúcar é promissor e apresenta correlação entre a presença de micélio em folhas primārias e a produção de chicotes nas plantas suscetíveis (DUARTE, 1976 e DUARTE e TOKESHI, 1978).

Foi comprovado por SILVA (1978) e SILVA e TOKESHI (1980) que é vâlida a seleção de plantas resistentes a U.scitaninea na fase de plântula, pois há correlação entre a reação à doença nas fases juvenil e adulta. Os mesmos autores obtiveram uma eficiência de seleção de 66,11 e 66,68\% para as progênies de PR 980 e CB 41-76, respectivamente.

0 método de pré-seleção de plântulas a $U$. seitaminea já é empregado pela Cooperativa Central dos Produtores de Açúcar e Ālcool do Estado de São Paulo - COPERSUCAR, que descarta anualmente 600.000 plântulas, 45 a 90 dias após a semeadura (SILVA, 1978 e SILVA e TOKESHI, 1980). 


\subsection{1 - Uso do vācuo na inoculação com U. scitcominea}

0 uso do vácuo na inoculação, em gemas, com U. scita minea foi utilizado por HIRSCHHORN (1949), TOFFANO (1965, 1966, 1966a), WALLER (1970), TOFFANO (1976) e SANGUINO e TOKESHI (1976).

Vários métodos de inoculação, em gemas, foram utilizados por HIRSCHHORN (1949). Observou que a inoculação por imersão numa suspensão concentrada de teliosporos, a um vácuo parcial e durante 15 a 20 minutos, foi a que deu maior percentagem de infecção. Comparações de métodos de inoculação foram, também realizadas por TOFFANO (1976). Verificou que a inoculação à vácuo de $380 \mathrm{~mm}$ de Hg foi a que deu maior percentagem de infecção.

WALLER (1970) utilizou vácuo de 160 e $400 \mathrm{~mm}$ de $\mathrm{Hg}$, durante três minutos,' obtendo maior percentagem de infecção na pres são de $160 \mathrm{~mm}$ de Hg. SANGUINO e TOKESHI (1976) utilizaram vácuo de $612 \mathrm{~mm}$ de $\mathrm{Hg}$, durante quatro minutos, concluindo que nos testes de resistência de cana-de-açúcar a $U$. scitominea, o uso do vácuo é pre judicial à brotação das gemas.

0 uso do vácuo na inoculação, em cariopses, com $U$. scitconinea foi utilizado por BLEICHER (1978) e BLEICHER e TOKESHI (1980). Verificaram que a inoculação à vácuo de $250 \mathrm{~mm}$ de Hg, duran te dois minutos, elimina a necessidade de descascamento das cariopses, para obtenção de alta eficiência de inoculação com U. scitaminea. Verificaram também que esse nível de vácuo prejudica a germina 
ção das cariopses.

Estudos com níveis de vácuo inferiores a $250 \mathrm{~mm}$ de $\mathrm{Hg}$ são necessários para avaliar seus efeitos na germinação de cariopses e colonização de plântulas por U. scitaminea.

2.2 - Influēncia de Microrganismos na Germinação e Desenvolvimen to de Plāntulas de Cana-de-Açūcar

Entre os fatores que afetam a qualidade das sementes encontra-se a presença de microrganismos. Muitas são as espécies de microrganismos patogênicos que podem ser transmitidos pelas sementes e causar doença nas prōprias sementes, nas plântulas, nas plantas adultas e mesmo nas sementes da geração seguinte (TOLEDO e MARCOS FILHO, 1977).

No programa de melhoramento genético da cana-de-açúcar, para obtenção de cultivares resistentes às doenças, são produzidas, anualmente, milhares de plântulas e freqüentemente surge pro blema na germinação. Estudos demonstraram que a maioria dos organis mos patogênicos, da parte aérea da cana-de-açúcar, podem parasitar as cariopses e que as condições climáticas, nas quais as plantas flo rescem e frutificam, favorecem o ataque por outros organismos comuns a outras gramíneas (TOKESHI, 1980).

0 primeiro relato de Helminthosporizon sacchori, em cariopses de cana-de-açúcar, foi feito por LOVELESS e SMITH (1956). 
Verificaram que o fungo foi o responsável pelo decréscimo na germ1nação, e morte de plântulas.

Foram citados como patógenos de plântulas de cana-de- açúcar os fungos H. rostratum, H. hawaiiensis, Curvularia Zunata e C. senegalensis (BYTHER e STEINER, 1969; BYTHER et alii, 1971; BYTHER e STEINER, 1972; KHURANA e SINGH, 1972; YANG, 1973 e RAMALLO, 1975). Geralmente, a infecção deixou de ser fatal em plântulas com duas a três semanas de idade (BYTHER e STEINER, 1972). Observações semelhantes foram feitas por RAMALLO (1975). BYTHER e STEINER (1972) observaram ainda maior mortalidade de plântulas originadas de cariopses com um ano de idade, possivelmente, devida a perda de vigor. No Brasil, os fungos dos gêneros Helminthosporizm, Curvularia e Fusarium apresentam-se, em alta frequência, em cariopses de cana-de-açúcar, e são responsáveis por boa parte da baixa gex minação e morte de plântulas. Os fungos dos gêneros Pestalotia, Pho ma e Cladosporium não possuem grande patogenicidade sobre as cariopses, mas contribuem para aumentar o efeito global causado pelos patógenos mais agressivos (SANGUINO, 1976 e SANGUINO e TOKESHI, 1980). Resultados semelhantes foram obtidos por SILVA (1978).

$$
\text { DUARTE (1976) e DUARTE e TOKESHI (1978) verificaram }
$$

a colonização dos tecidos de plântulas de cana-de-açúcar por Helmin thosporium sp, Phoma sp e Curvularia sp. Estes resultados foram con firmados por BLEICHER (1978), ao examinar plântulas mortas.

Com relação aos contaminantes de esporos de $U$. scita 
minea, DUARTE (1976), DUARTE e TOKESHI (1978a) e SILVA (1978) obser varam que $F$. moniliforme e Fusarium sp foram os mais freqüentes es mais patogênicos às plântulas de cana-de-açūcar. PLOPER e RAMALLO (1979) verificaram que U. scitcominea produz substâncias com proprie dades antibióticas, as quais podem interferir na mortalidade de plân tulas originadas de cariopses inoculadas.

Pelos trabalhos revisados, observa-se que os contaminantes patogênicos às plântulas de cana-de-açūcar, presentes nas cariopses e nos esporos de U. scitominea, podem interferir no método de inoculação em cariopses. Pelos motivos expostos, verifica-se que hā necessidade de utilizarem-se esporos e cariopses de melhor qualidade para obter-se maior eficiência no método de inoculação.

\section{3 - Influência do Substrato na Germinação e Desenvolvimento de plântulas de Cana-de-Açūcar}

Para germinação de cariopses de cana-de-açūcar, MANGELSDORF (1966) recomenda como substrato barro-arenoso permeável. Quatro substratos foram comparados por GIBE e PANOL (1969), sendo que a melhor germinação foi obtida quando utilizaram três partes de torta de filtro Oliver para uma de cinza.

DONELAN (1980) verificou melhor desenvolvimento de plântulas quando resto de fibra de coco foi misturado ao solo. Atri buiu esse melhor desenvolvimento às melhores propriedades físicas, drenagem e aeração desse substrato. 
Os substratos āgar-āgua (22 g de ägar por litro de água) e solo (três partes de torta de filtro 01iver para uma de solo não esterilizado) foram comparados por SILVA (1978) para as cultivares $C B$ 41-76 e PR 980. A germinação foi significativamente maior no substrato ágar-água para a cultivar CB 41-76, tendo ocorrido o conträrio para a cultivar PR 980 .

SILVA (1978) observou que a maior mortalidade de plân tulas, após o transplante, ocorreu quando foi utilizado o substrato ágar-água; entretanto, este substrato foi superior ao solo para seleção de plântulas resistentes a $U$. scitaminea.

Mais estudos são necessārios para verificar-se a influência dos substratos na germinação de cariopses, colonização de plântulas por U. scitominea e mortalidade de plântulas após o trans plante. 
10.

3. MATERIAL E METODOS

3.1 - Inōculo

3.1.1 - Obtenção, armazenamento e teste de germinação

Os teliosporos de $U$. scitcominea foram produzidos em cana-de-açúcar, cultivar CP 52-1, em condições de casa de vegetação. Visando-se obter o máximo possível de teliosporos, livres de fungos contaminantes, o chicote foi revestido com saco de papel semipermeável. A coleta e o armazenamento dos teliosporos foram efetuados de acordo com as recomendações de MATA (1975) e MATA e TOKESHI (1976). Nos ensaios, foram utilizados teliosporos coletados em dezembro de 1978 e janeiro de 1980 com 99 e $98 \%$ de germinação, respectivamente. 
11.

\section{1 .2 - Determinação qualitativa dos fungos contaminantes dos esporos de $U$. scitaminea}

Dos teliosporos a serem analisados,foi preparada uma suspensão na concentração de $6 \times 10^{5}$ esporos/ml. Em seguida, foram retiradas, dessa suspensão, quatro alíquotas de $0,5 \mathrm{ml}$, que foram semeadas sobre o meio ágar-água (18 g de ágar por 1 itro de água),con tido em placas de Petri. Posteriormente, as placas foram incubadas sob condições de luz contínua (fornecida por nove lâmpadas fluorescentes, de 40 watts, luz do dia, a uma distância de aproximadamente um metro) e temperatura de $29^{\circ} \mathrm{C}$, durante séis dias. Após esse perío do, foi feita a identificação dos fungos contaminantes de acordo com BARNETT e HUNTER (1972).

Os fungos contaminantes encontrados, nos teliosporos de U. scitaminea, foram Monilia sp e Penicillium sp para os coletados em dezembro de 1978 e Monilia sp para os de janeiro de 1980.

\section{2 - Cariopses}

\subsection{1 - Origem, beneficiamento e armazenamento}

Nos ensaios, foram utilizadas cariopses de cana-de-açúcar, obtidas por polinização livre das cultivares IAC 48/65 e Co 419 (provenientes da Estação de Floração e Cruzamento de Serra do Ouro, Alagoas, pertencente ao Programa Nacional de Melhoramento da Cana-de-Açūcar - PLANALSUCAR) e da cultivar NA 56-79 (provenientes de dois lotes da Estação Experimental Frederico de Menezes Veiga, 
Rio de Janeiro, pertencente ao PLANALSUCAR).

As cariopses sofreram prë-1impeza, de acordo com o processo preconizado por SILVA (1974). Posteriormente, for am submetidas à ventilação, com uma força de $9,6 \mathrm{mg} / \mathrm{cm}^{2}$ (abertura do tubo 13), durante dois minutos, no assoprador marca Equilabor (BLEICHER, 1978 e BLEICHER e TOKESHI, 1980a). Em seguida, foram passadas em pe neira 20 (20 malhas/polegada quadrada), com a finalidade de separar-se, o máximo possível, os pedúnculos das cariopses.

As cariopses beneficiadas foram armazenadas na câmara seca do Laboratório de Análise de Sementes da ESALQ. A câmara se ca teve umidade relativa controlada para $35 \%$ aproximadamente e temperatura média de $23^{\circ} \mathrm{C}$.

\subsection{2 - Teste de germinação}

As cariopses foram desinfetadas com hipoclorito de cálcio (hth), com $65 \%$ de cloro ativo, na dosagem de $1 \mathrm{~g} / 100 \mathrm{ml}$ de água destilada, durante cinco minutos. Em seguida,foram semeadas 50 cariopses por placa de Petri, contendo papel de filtro umedecido.Fo ram utilizadas luz continua (semelhante à de 3.1.2), temperatura de $29^{\circ} \mathrm{C} \pm 2{ }^{\circ} \mathrm{C}$ e um total de quatro placas por cultivar.

A contagem de germinação foi realizada aos sete dias após a instalação do teste, e a avaliação das plântulas efetuada de acordo com as prescrições indicadas pelas Regras para Anālise de Se 
mentes (BRASIL. Ministério da Agricultura, 1976).

0 poder germinativo das cariopses foi: 'IAC $48 / 65^{\prime}=$ $=49 \% \dot{\prime}^{\prime} \operatorname{CO} 419^{\prime}=36 \%$ ' $^{\prime} \mathrm{NA} 56-79^{\prime}($ lote 1$)=88 \%$ e 'NA 56-79' (lote 2) $=56 \%$.

\subsection{3 - Determinação quantitativa dos fungos contaminantes}

Para determinação dos fungos contaminantes das cariopses foi utilizado o teste com papel de filtro.A desinfecção das cariopses foi semelhante à descrita em 3.2.2. Para manter-se a umidade, foi colocada, na placa de Petri, uma camada de algodão umedecida, abaixo dos papéis de filtro. A amostra consistiu de 400 cariopses, sendo semeadas 50 por placa. Posteriormente, as mesmas foram incubadas sob cọndições de luz contỉnua (semelhante à de 3.1.2) e temperatura de $29^{\circ} \mathrm{C}$, durante seis dias.

Após o período de incubação, os fungos presentes nas cariopses foram identificados de acordo com BARNETT e HUNTER(1972).

\subsubsection{1 - Testes de patogenicidade com Colletotri- chum falcatum}

0 fungo $C$. falcatum foi isolado de cariopses de cana-de-açúcar, cultivar CO 419, durante o teste de germinação, e para testar-se a sua patogenicidade, o inóculo foi produzido em meio de aveia-ágar (100 g de aveia e $18 \mathrm{~g}$ de ágar por litro de água) sob condições de luz contínua (semelhante à de 3.1.2) e temperatura de 29 
${ }^{\circ} \mathrm{C}$, durante vinte dias. A concentração do inóculo utilizada foi de $4 \times 10^{6}$ conídios/m1 (KIMATI, 1975).

Os testes de patogenicidade foram realizados em plân tulas e em folhas de cana-de-açücar.

As cariopses, da cultivar CO 419, foram desinfetadas como descrito em 3.2.2 e colocadas para germinar em placas de Petri contendo ágar-água. Após a germinação, as plântulas foram examinadas ao microscópio estereoscópico e somente as aparentemente livres de fungos foram transplantadas para placas de Petri contendo āgar-água. Duas gotas da suspensão de esporos foram colocadas por plântula (SANGUINO, 1976).

Foram utilizadas três repetições por tratamento, sen do que cada repetição foi constituída por uma placa com dez plântulas.

A inoculação nas folhas foi realizada quando as plan tas (cultivar CB 41-76) estavam com dois meses de idade e consistiu em colocar-se uma gota da suspensão de esporos no terço inferior da nervura central das quatro primeiras folhas abertas, e provocar-se um ferimento com uma agulha lanceolada (ABBOTT, 1938).

Foram utilizadas três repetições por tratamento, sen do que cada repetição foi constituída por um vaso com uma planta. 0 teste foi conduzido em condições de casa de vegetação.

Nos dois métodos de inoculação utilizados, os tratamentos considerados foram: inoculada e não inoculada (testemunha). 
As testemunhas foram tratadas com ägua destilada esterilizada, e a avaliação feita dez dias após a inoculação.

\section{3 - Influēncia do Vācuo na Germinação de Cariopses}

As cariopses, da cultivar IAC $48 / 65$, foram desinfeta das com 1-óxido de zinco-2-piridinetiol (Zinco Omadine) com $48 \%$ de princípio ativo, na dosagem de $3 \mathrm{ml}$ do produto comercial por litro de água, durante duas horas e, depois, lavadas com água destilada (BLEICHER, 1978).

Posteriormente, as cariopses foram colocadas em fras cos de Kitassato, contendo $200 \mathrm{ml}$ de água destilada esterilizada, e submetidas à vácuo de $0,50,100,150$ e $200 \mathrm{~mm}$ de $\mathrm{Hg}$, durante dois minutos. Em seguida, foram semeadas 100 cariopses por bandeja de aluminio $(4 \times 19 \times 28 \mathrm{~cm})$, contendo $400 \mathrm{ml}$ de substrato esterilizado àgar-água (15 gramas de āgar por litro de água destilada). Após a semeadura, as bandejas foram cobertas com vidro transparente e mantidas sob condições de luz continua (semelhante à de 3.1.2) e tempe ratura de $29^{\circ} \mathrm{C} \pm 2{ }^{\circ} \mathrm{C}$, durante sete dias (BLEICHER, 1978). Decorrido esse período, as cariopses germinadas foram contadas e a avaliação das plântulas procedida como em 3.2.2.

0 delineamento experimental utilizado foi o inteiramente casualizado com cinco repetições por tratamento (níveis de vā cuo), sendo que cada parcela foi constituída por uma bandeja com cem 
cariopses.

\section{4 - Influência do Vãcuo na Colonização de Plântulas por U. sci taminea}

As cariopses, da cultivar IAC 48/65, tendo sido desinfetadas como descrito em 3.3, foram imersas numa suspensão de es poros de $U$. scitaminea na concentração de $6 \times 10^{6}$ esporos/ml e submetidas à vácuo de $0,50,150$ e $250 \mathrm{~mm}$ de $\mathrm{Hg}$, durante dois minutos. No preparo da suspensão de esporos foram adicionadas duas gotas de Tweẹn 20 a $20 \%$.

A semeadura (200 cariopses por bandeja) e incubação foram realizadas como descritas em 3.3 .

As reinoculações, no segundo e sexto dia apös a semeadura, foram feitas por pulverização, com uma suspensão de esporos de U. scitaminea na concentração de $6 \times 10^{6}$ esporos/m1 (BLEICHER, 1978).

Doze dias após a semeadura das cariopses, sessenta plântulas por repetição, de cada tratamento, foram coletadas ao aca so e transferidas para tubos de cultura, pracedendo-se à coloração dos tecidos pelo método de POPP (1958), com eliminação das lavagens por não interferirem nos resultados,

Concluído o processo de coloração, trinta plântulas por repetição de cada tratamento, for am examinadas ao microscópio, para determinar-se a presença ou ausência de micēlio interno de $U$. scitaninea. As plântulas que apresentavam micélio interno, na raiz 
primäria, no mesocótilo ou nas folhas, foram consideradas coloniza das .

0 delineamento experimental utilizado foi o inteiramente casualizado com seis repetições por tratamento (níveis de vácuo), sendo que cada parcela foi constituida por trinta plântulas.

3.5 - Comparação de Métodos de Inoculação na Colonização de Plân tulas por U. scitaminea

As cariopses, das cultivares NA 56-79 (1ote 2) e CO 419, foram desinfetadas como descrito em 3.3. Três mêtodos de inocu lação foram utilizados: a) as cariopses foram imersas numa suspensão de esporos de $U$. scitaminea, na concentração de $6 \times 10^{6}$ esporos/ /m1, e agitadas durante dois minutos; b) semelhante ao método a , po rēm submetidas à vācuo de $250 \mathrm{~mm}$ de $\mathrm{Hg}$, durante dois minutos; c) as cariopses foram inoculadas, no dia da semeadura, por pulverização de esporos, na concentração jä citada. No preparo da suspensão de esporos foram adicionadas duas gotas de Tween 20 .

A semeadura de 150 e 250 cariopses por bandeja para as cultivares NA 56-79 (lote 2) e CO 419, respectivamente, e a incu bação foram efetuadas como descritas em 3.3. As reinoculações no se gundo e sexto dia após a semeadura, coleta das plântulas, coloração dos tecidos e avaliação foram efetuadas como em 3.4 .

0 delineamento experimental utilizado foi o inteiramente casualizado, num esquema fatorial $2 \times 3$, sendo o primeiro fa- 
tor as cultivares e o segundo os métodos de inoculação. Foram utili zadas quatro repetições, sendo que cada parcela foi constituída por trinta plântulas.

\section{6 - Influência da Cultivar e Inoculação com U. scitáminea na Mortalidade de Pläntulas}

As cariopses, das cultivares CO 419 e NA 56-79 (lote 1), foram desinfetadas como descrito em 3.3. As cariopses não inocu ladas (testemunha) foram imersas em água destilada esterilizada, dụ rante dois minutos; e as cariopses inoculadas foram imersas na suspensão de esporos de $J$. scitaminea e submetidas à vácuo de $50 \mathrm{~mm}$ de Hg, durante dois minutos.

Das cultivares CO 419 e NA 56-79 (lote 1), foram semeadas, respectivamente, 250 e 100 cariopses por bandeja de aluminio contendo o substrato esterilizado vermiculita (700 cc de vermiculita, de origem Minebra e tipo no 2, mais 400 cc de água destilada), coberto com papel higiênico de folha dupla, marca Delsey.

A incubação e as reinoculações, no segundo e sexto dia após a semeadura, foram efetuadas como descritas em 3.3 e 3.4, respectivamente.

Oito dias após a semeadura, cinqüenta plântulas normais, de cada bandeja, foram transplantadas para caixa de madeira (9 $\times 31 \times 41 \mathrm{~cm})$ contendo uma mistura de solo esterilizado e vermiculita na proporção de 1:1 e mantidas em condições de casa de vege- 
tação. As caixas foram colocadas em câmara úmida, sendo esta retira da, paulatinamente, do segundo ao quarto dia após o transplante. No terceiro dia após o transplante, e a partir daí, semanalmente, por três semanas consecutivas foram feitas pulverizações com dissulfeto de tetrametil thiuram (Auram 700) com 70\% do principio ativo, na dosagem de um grama do produto comercial por $1 \underline{i}$ tro de água. Também foram feitas adubações semanais com Greenzit A (Ciba Geigy), constituido por NPK $(9: 18: 6)$ e micronutrientes, na do sagem de $3 \mathrm{ml}$ por litro de ägua.

A contagem das plântulas sobreviventes foi efetuada trinta dias após o transplante.

O delineamento experimental utilizado foi o inteiramente casualizado, num esquema fatorial $2 \times 2$, sendo o primeiro fator as cultivares e o segundo a inoculação. Foram utilizadas oito re petições, sendo que cada parcela foi constituída por uma caixa com cinqüenta plântulas.

3.7 - Relação entre a Presença de Micēlio de U. scitominea nas Fô Ihas e o Aparecimento de Chicotes

As plantas utilizadas neste ensaio, provenientes do ensaio descrito em 3.6, são referentes às cariopses inoculadas das duas cultivares. Foram utilizadas cem plantas por cultivar, retiradas ao acaso, das oito repetições, aos quarenta dias após o transplante. As plantas foram transferidas, individualmente, para sacos de polietileno contendo solo esterilizado e, em seguida, numeradas. 
Vinte dias depois, uma parte das três folhas expandidas mais próximas do ápice, de cada planta, foi destacada e dividida em porções de aproximadamente $3 \mathrm{~cm}$ de comprimento. Quatro dessas porções, de cada planta, foram retiradas ao acaso e submetidas ao processo de coloração descrito em 3.4 .

A avaliação foi expressa em presença ou ausência de micélio interno nas amostras dos tecidos foliares examinadas ao microscópio.

As plantas permaneceram 90 dias nos sacos de polietileno, anotando-se o número da planta que apresentava chicote, a qual era eliminada em seguida. Após esse período, as plantas restan tes foram podadas e transferidas para o campo do Departamento de Fi topatologia da ESALQ, onde se cantinuou, até 14 meses após a semeadura, a anotar o aparécimento de chicote e a eliminação da planta correspondente.

3.8 - Influência do Fotoperíodo na Colonização de Plântulas por U. scitaminea e na Mortalidade de Plântulas

Este ensaio consistiu na comparação dos fotoperíodos de 12 e 24 horas de luz, quanto à colonização de plântulas por $U$. scitominea e à mortalidade de plântulas após o transplante.

As cariopses, da cultivar NA 56-79 (lote 2), foram desinfetadas como descrito em 3.3. Posteriormente, foram imersas nu ma suspensão, na concentração de $6 \times 10^{6}$ esporos $/ \mathrm{m} 1$, e agitadas du- 
rante dois minutos. A semeadura (300 cariopses por bandeja) e as reinoculações no segundo e sexto dia apōs a semeadura foram efetuadas como descritas em 3.6 e 3.4 , respectivamente.

A incubação foi feita no germinador de sementes, FANEM Ltda. - Modelo 348 , à temperatura constante de $30^{\circ} \mathrm{C}$ com 1 uz con tínua (fornecida por oito lâmpadas fluorescentes, de 40 watts, luz do dia). As bandejas, correspondentes ao fotoperíodo de doze horas de luz, foram cobertas, individualmente, com plástico preto.

A coleta das plântulas, coloração dos tecidos e avaliação das plântulas colonizadas foram efetuadas como em 3.4 .

Para determinar-se a influência do fotoperíodo na mor talidade de plântulas, cinqüenta plântulas, de cada bandeja, foram transplantadas para caixa de madeira, adotando-se o mesmo procedimento de 3.6. As adubações e pulverizações apōs o transplante e a contagem das plântulas sobreviventes seguiram também os procedimentos de 3.6 .

o delineamento experimental utilizado foi o inteiramente casualizado, com oito repetições por tratamento (fotoperíodos). A parcela foi constituída por: trinta plântulas (colonização) e uma caixa com cinqüenta plântulas (mortalidade). 
22.

3.9 - Influência do Substrato e Inoculação com U. scitcominea na Germinação de Cariopses, Colonização e Mortalidade de Plān tulas

As cariopses, da cultivar NA 56-79 (lote 2), foram desinfetadas como em 3.3. Os substratos utilizados foram ágar-água e vermiculita cujas composições foram discriminadas, respectivamente, em 3.3 e 3.6 .

\subsection{1 - Influência do substrato e inoculação na germinação}

Os tratamentos considerados foram: a) cariopses. inoculadas e semeadas em ágar-água; b) cariopses inoculadas e semeadas em vermiculita; c) cariopses não inoculadas (testemunha) e semeadas em ágar-água e d) cariopses não inoculadas (testemunha) e semeadas em vermiculita.

Foram semeadas 400 cariopses por bandeja. A inoculação antes da semeadura, as reinoculações no segundo e sexto dia após a semeadura e a incubação foram efetuadas como descritas em 3.8, 3.4 e 3.3 , respectivamente.

A contagem de germinação foi realizada aos doze dias e a avaliação das plântulas procedida como em 3.2.2.

3.9.2 - Influência do substrato na colonização

Doze dias após a semeadura, sessenta plântulas por bandeja, dos tratamentos $\underline{a}$ e $\underline{b}(3.9 .1)$, foram coletadas ao acaso e 
transferidas para tubo de cultura. A coloração dos tecidos e a avaliação das plântulas colonizadas foram efetuadas como em 3.4 .

\subsection{3 - Influência do substrato e inoculação na mortalidade}

Cinqüenta plântulas por bandeja, de cada tratamento (3.9.1), foram transplantadas para caixa de madeira, adotando-se o mesmo procedimento de 3,6. As adubações e pulverizações após o trans plante e a contagem das plântulas sobreviventes seguiram também os procedimentos de 3.6 .

\section{9 .4 - Delineamento experimental}

O delineamento experimental foi o inteiramente casua lizado, com oito repetições por tratamento. Na germinação e mortali dade de plântulas, o mesmo foi utilizado em esquema fatorial $2 \times 2$, sendo o primeiro fator os substratos e o segundo a inoculação.A par cela foi constituída por: uma bandeja com quatrocentas cariopses (germinação), trinta plântulas (colonização) e uma caixa com cinqüen ta plântulas (mortalidade).

\subsection{0 - Fungos Encontrados nas Plāntulas Mortas}

Nos ensaios descritos em 3.6, 3.8 e 3.9.3, após o transplante para as caixas de madeira até o dia da contagem das plân tulas sobreviventes, as plẩntulas que iam morrendo, de cada tratamento, eram colocadas num mesmo vidro contendo Hyamine a $0,1 \%$ (TUI- 
TE, 1969) e armazenadas, em geladeira, a $5^{\circ} \mathrm{C}$.

Terminada a coleta, as plântulas foram transferidas para tubos de cultura, procedendo-se a coloração dos tecidos de ma neira semelhante à de 3.4 .

Concluído o processo de coloração, mais de $50 \%$ das plântulas mortas, de cada tratamento e de cada ensaio, foram examinadas ao microscópio para determinar-se a presença de fungos internos na raiz, no mesocótilo ou nas folhas. Os fungos foram identificados pela chave de classificação de BARNETT e HUNTER (1972) e pelas características morfológicas, de alguns'fungos, descritas por DUARTE (1976) e DUARTE e TOKESHI (1978).

\subsection{1 - Anālise Estatîstica dos Dados}

Inicialmente, todos os dados expressos em percentagens foram transformados em arc sen $\sqrt{\mathrm{p} / \overline{100}}$, onde $\underline{p}$ significa a percentagem considerada. Antes porém, os valores de piguais a zero fo ram substituídos por $100 / 4 n$, onde $\underline{n}$ significa o denominador usado no cálculo das percentagens (BARTLETT, 1947).

Nas Tabelas 1 e 2, encontram-se os esquemas da anāli se de variância adotados para os ensaios sem e com esquema fatorial, respectivamente. 
Tabela 1 - Esquema da anālise de variância adotado para os ensaios sem esquema fatorial.

\begin{tabular}{lc}
\hline Causa de Variação & G.L. \\
\hline Tratamentos & $\mathrm{t}-1$ \\
Resíduo & $\mathrm{m}-\mathrm{t}$ \\
\hline Total & $\mathrm{m}-1$ \\
\hline
\end{tabular}

onde:

$t=$ nümero de tratamentos;

$\mathrm{m}=$ número total de parcelas existenté.

Tabela 2 - Esquema da análise de variância adotado para os ensaios com esquema fatorial.

\begin{tabular}{lc}
\hline Causa de Variação & G.L. \\
\hline Primeiro fator (A) & $s-1$ \\
Segundo fator (B) & $v-1$ \\
Interação A x B & $(s-1)(v-1)$ \\
\hline (Tratamentos) & $(s v-1)$ \\
Resíduo & sv (r-1) \\
\hline Total & svr-1 \\
\hline
\end{tabular}

onde:
$s$ = número de níveis do primeiro fator;
$\mathrm{v}=$ nümero de níveis do segundo fator;
$r=$ número de repetições. 
Para os casos em que o teste $F$ foi significativo, e tendo-se mais de dois tratamentos, as comparações entre as médias dos tratamentos foram feitas pelo teste de Tukey, ao nível de $5 \%$ de probabilidade. Para indicar-se que dois ou mais tratamentos não diferiram estatisticamente, acrescentou-se, após as suas médias (dados transformados), letras minüsculas iguais.

A relação entre a presença de micélio de U. scitooninea nas folhas e o aparecimento de chicotes foi analisada estatist camente pelo teste qui-quadrado $\left(X^{2}\right)$. Para verificar-se se as plantas com micélio diferiam estatisticamente das plantas sem micélio, quanto ao período de produção de chicotes, utilizou-se também o tes te qui-quadrado $\left(x^{2}\right)$.

Neste trabalho, o termo plantas sem micélio nas folhas é equivalente a plantas nas quais não foi detectado micélio nas folhas. 
4.1 - Determinação Quantitativa dos Fungos Contaminantes de Cariopses

Os fungos encontrados nas cariopses, das cultivares IAC 48/65, CO 419 e NA 56-79 (lote 2), são apresentados na Tabe1a 3 .

\subsection{1 - Testes de patogenicidade com C. falcatum}

Foi observada mortalidade de plântulas ('CO 419') em 80,00\%, e nas plantas ('CB 41-76') verificou-se a formação de lesões e frutificação do fungo na nervura central das folhas. 
Tabela 3 - Fungos encontrados nas cariopses de três cultivares de cana-de-açúcar .

\begin{tabular}{|c|c|c|c|}
\hline \multirow{2}{*}{ FUNGOS CONTAMINANTES } & \multicolumn{3}{|c|}{$\begin{array}{c}\% \text { de Cariopsesal Contaminadas } \\
\text { das Cultivares }\end{array}$} \\
\hline & IAC $48 / 65$ & Co 419 & $\begin{array}{l}\text { NA } 56-79 \\
\text { (lote 2) }\end{array}$ \\
\hline Altemaria spp & 0,25 & 0,00 & 0,50 \\
\hline Chaetomium sp & 5,00 & 0,00 & 0,75 \\
\hline Colletotrichum falcatum & 0,00 & 10,50 & 0,00 \\
\hline Curvularia spp & 5,25 & 0,00 & 0,50 \\
\hline Epicocum sp & 0,00 & 8,00 & 3,00 \\
\hline Helminthosporium spp & 0,00 & 0,50 & 1,25 \\
\hline Nigrospora spp & 1,00 & 0,00 & 2,50 \\
\hline Penicizlium sp & 0,50 & 3,50 & 0,50 \\
\hline Pestalotia sp & 0,25 & 0,00 & 0,00 \\
\hline Phoma sp & 1,00 & 5,00 & 13,25 \\
\hline Rhizoctonia sp & 0,00 & 0,00 & 0,25 \\
\hline septoria sp & 0,00 & 0,50 & 0,00 \\
\hline Indeterminados & 1,25 & 0,00 & 0,75 \\
\hline Total & 14,50 & 28,00 & 23,25 \\
\hline
\end{tabular}

a/ A amostra consistiu de 400 cariopses por cultivar. 


\section{2 - Influēncia do Vācuo na Germinação de Cariopses}

A anālise de variância revelou valor de $F$ significativo, ao nível de $1 \%$ de probabilidade, para os vārios níveis de vācuo utilizados.

As médias dos dados em percentagem de germinação, e transformados em arc sen $\sqrt{\mathrm{p} 7 \overline{100}}$, acham-se na Tabela 4 .

Tabela 4 - Influência do vácuo na germinação de cariopses da cultivar IAC $48 / 65$.

\begin{tabular}{ccc}
\hline \multirow{2}{*}{$\begin{array}{c}\text { VÁCUO } \\
(\mathrm{mm} \text { de Hg })\end{array}$} & $(\%)$ & MÉDIA \\
\cline { 2 - 3 } & 39,40 & $38,85 \mathrm{a}$ \\
50 & 37,40 & $37,70 \mathrm{ab}$ \\
100 & 32,00 & $34,44 \mathrm{~b}$ \\
150 & 32,25 & $34,56 \mathrm{~b}$ \\
200 & 31,60 & $34,18 \mathrm{~b}$ \\
\hline
\end{tabular}

C.V. $(\%)=5,73$

D.M.S. (5\%): $\left\{\begin{array}{lll}(5 \text { repetições } \times 5 \text { repetições })=3,92 \\ (5 \text { repetições } \times 4 \text { repetiçôes })=4,16\end{array}\right.$

a/ Proveniente de 5 repetições, exceto para $150 \mathrm{~mm}$ de $\mathrm{Hg}$ com 4; cada repetição foi constituída por 100 cariopses.

4.3 - Influência do Vãcuo na Colonizaçăo de Plāntulas por U. $8 c i$ tominea

Para os dadós de percentagem de plântulas colonizadas por U. scitoninea, a análise de variância revelou que não houve 
diferença significativa, ao nível de $5 \%$ de probabilidade, para os värios níveis de vācuo utilizados.

As médias dos dados em percentagem de plântulas colo nizadas são apresentadas na Tabela 5 .

Tabela 5 - Influência do väcuo na colonização de plântulas por $U$. scitaminea. Cultivar IAC 48/65.

\begin{tabular}{|c|c|}
\hline 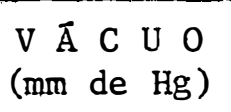 & $M \underset{(\%)}{\mathrm{D} I \mathrm{I}}$ \\
\hline 0 & 45,56 \\
\hline 50 & 49,44 \\
\hline 150 & 48,89 \\
\hline 250 & 48,03 \\
\hline
\end{tabular}

C.V. $(\%)=12,75$

a/ Proveniente de 6 repetições, cada uma constituída por 30 plântulas.

4.4 - Comparação de Métodos de Inoculação na Colonização de.Plān tulas por $U$. scitominea

A análise de variância não acusou diferença significativa, ao nível de $5 \%$ de probabilidade, para métodos de inoculação, cultivares e interação métodos de inoculação x cultivares.

As médias dos dados em percentagem de plântulas colo nizadas, referentes aos métodos de inoculação e cultivares, são apre sentadas na Tabela 6 . 
Tabela 6 - Comparação de métodos de inoculação na colonização de plântulas, por U. scitominea, de duas cultivares de cana-de-açūcar.

\begin{tabular}{|c|c|c|c|c|}
\hline \multirow{2}{*}{ CULT IVAR } & \multicolumn{3}{|c|}{$\begin{array}{l}\text { Média }{ }^{a} \text { em \% para os } \\
\text { Métodos de Inoculação }\end{array}$} & \multirow{2}{*}{ Média } \\
\hline & Sem vácuo & Com vācuo & Pulverização & \\
\hline CO 419 & 19,17 & 24,17 & 22,50 & 21,95 \\
\hline $\begin{array}{l}\text { NA } 56-79 \\
\text { (lote 2) }\end{array}$ & 18,33 & 18,34 & 8,34 & 15,00 \\
\hline Média & 18,75 & 21,26 & 15,42 & \\
\hline
\end{tabular}

C.V. $(\%)=28,65$

a/ Proveniente de 4 repetições, cada uma constituída por 30 plânt $\underline{u}$ las.

b/ De $250 \mathrm{~mm}$ de $\mathrm{Hg}$.

\section{5 - Influência da Cultivar e Inoculação com U. scitcominea na Mortalidade de Plāntulas}

$\mathrm{Na}$ anālise de variância foram encontrados valores de F significativos, ao nível de $1 \%$ de probabilidade, para os fatores cultivares e inoculação. Entretanto, a interação desses fatores não foi significativa, ao nível de $5 \%$ de probabilidade.

As médias dos dados em percentagem de plântulas mortas, e transformados em arc sen $\sqrt{\mathrm{p}} 7 \overline{100}$, referentes aos fatores cultivares e inoculação, encontram-se na Tabela 7 . 
Tabela 7 - Influência da inoculação com U. scitaminea na mortalidade de plântulas de duas cultivares de cana-de-açúcar.

\begin{tabular}{|c|c|c|c|c|c|c|}
\hline \multirow{2}{*}{ CULTIVAR } & \multicolumn{2}{|c|}{$M \overline{(\%)}$} & \multirow{2}{*}{ Média } & \multicolumn{2}{|c|}{$\begin{array}{l}\mathrm{ME} \mathrm{D} \mathrm{I} \mathrm{A} \stackrel{\text { a }}{ } \\
(\operatorname{arc} \operatorname{sen} \sqrt{\mathrm{p} / 100})\end{array}$} & \multirow{2}{*}{ Média } \\
\hline & Test. & Inoc. & & Test. & Inoc. & \\
\hline CO 419 & 13,50 & 23,29 & 18,40 & 20,85 & 27,80 & $24,33 a$ \\
\hline $\begin{array}{l}\text { NA } 56-79 \\
(\text { lote } 1)\end{array}$ & 4,00 & 16,50 & 10,25 & 10,62 & 23,52 & 17,07 \\
\hline Média & 8,75 & 19,90 & & 15,74 & 25,66 & \\
\hline
\end{tabular}

C.V. $(\%)=34,29$

a/ Proveniente de 8 repetições, cada uma constituỉda por 50 plântulas.

Obs.: Test. = Testemunha; Inoc. = Inoculada.

4.6 - Relação entre a Presença de Micēlio de U. scitconinea nas Folhas e o Aparecimento de Chicotes

Nas Tabelas 8 e 9 encontram-se os resuliados, referen tes ao estudo da relação entre a presença de micélio nas folhas e o aparecimento de chicotes, para as cultivares CO 419 e NA 56-79 (10te 1), respectivamente. Por outro lado, nas Tabelas 10 e 11 são apre sentados os resultados, referentes às comparações das plantas com micélio e sem micélio nas folhas quanto ao período de produção de chicotes, para as cultivares CO 419 e NA 56-79 (lote 1), respectiva mente. 
Tabela 8 - Relação entre a presença de micélio de $U$. scitaminea nas folhas e o aparecimento de chicotes. Cultivar C0 419.

\begin{tabular}{|c|c|c|c|}
\hline \multirow{2}{*}{$\begin{array}{l}\text { MICÉLIO } \\
\text { NAS FOLHAS }\end{array}$} & \multicolumn{2}{|c|}{ CHICOTE } & \multirow{2}{*}{ Total } \\
\hline & Com & Sem & \\
\hline Presente & $31(20,16)$ & $1(11,84)$ & 32 \\
\hline Ausente & $32(42,84)$ & $36(25,16)$ & 68 \\
\hline Tota1 & 63 & 37 & 100 \\
\hline \multicolumn{4}{|c|}{$x_{c}^{2}=23,17 \begin{array}{c}\text { (teste qui-quadrado significativo ao nîvel de } 0,1 \% \text { de pro } \\
\text { babilidade) }\end{array}$} \\
\hline
\end{tabular}

Tabela 9 - Relação entre a presença de micélio de U. scitaminea nas folhas e o' aparecimento de chicotes. Cultivar NA 56-79 (lote 1).

\begin{tabular}{|c|c|c|c|}
\hline \multirow{2}{*}{$\begin{array}{c}\text { MICÉLIO } \\
\text { NAS FOLHAS }\end{array}$} & \multicolumn{2}{|c|}{ CHICOTE } & \multirow{2}{*}{ Total } \\
\hline & Com & Sem & \\
\hline Presente & $34(23,56)$ & $4(14,44)$ & 38 \\
\hline Ausente & $28(38,44)$ & $34(23,56)$ & 62 \\
\hline Totạ1 & 62 & 38 & 100 \\
\hline \multicolumn{4}{|c|}{$\begin{array}{c}\chi_{c}^{2}=19,64 \begin{array}{c}\text { (teste qui-quadrado significativo ao nível de } 0,1 \% \text { de pro } \\
\text { babilidade) }\end{array}\end{array}$} \\
\hline
\end{tabular}


Tabela 10 - Comparação das plantas com micélio e sem micélio de $U$. scitominea nas folhas, quanto ao período de produção de chicotes. Cultivar co 419.

\begin{tabular}{|c|c|c|c|}
\hline \multirow{2}{*}{$\begin{array}{c}\text { MICÉLIO } \\
\text { NAS FOLHAS }\end{array}$} & \multicolumn{2}{|c|}{ PERĨODO DE PRODUÇÃO } & \multirow{2}{*}{ Total } \\
\hline & atē 4 meses & 5-14 meses & \\
\hline Presente & $30(15,75)$ & $1(15,25)$ & 31 \\
\hline Ausente & $2(16,25)$ & $30(15,75)$ & 32 \\
\hline Total & 32 & 31 & 63 \\
\hline$\chi_{c}^{2}=51,63 \quad$ (te & $\begin{array}{l}\text { qui-quadrado s } \\
\text { dade) }\end{array}$ & icativo ao ní & $0,1 \%$ \\
\hline
\end{tabular}

Tabela 11 - Comparação das plantas com micélio e sem micélio de $U$. scitominéa nas folhas, quanto ao período de produção de chicotes. Cultivar NA 56-79 (lote 1).

\begin{tabular}{|c|c|c|c|}
\hline \multirow{2}{*}{$\begin{array}{c}\text { MICÉLIO } \\
\text { NAS FOLHAS }\end{array}$} & \multicolumn{2}{|c|}{ PERIODO DE PRODUÇÃO } & \multirow{2}{*}{ Total } \\
\hline & atē 4 meses & $5-14$ meses & \\
\hline Presente & $29(16,45)$ & $5(17,55)$ & 34 \\
\hline Ausente & $1(13,55)$ & $27(14,45)$ & 28 \\
\hline Total & 30 & 32 & 62 \\
\hline \multicolumn{4}{|c|}{ 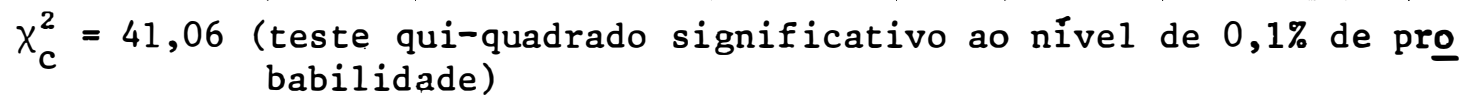 } \\
\hline
\end{tabular}


Na Figura 1 encontra-se a representação grāfica das percentagens mensais de produção de chicotes de $U$. scitcominea, pelas cultivares CO 419 e NA 56-79 (lote 1).

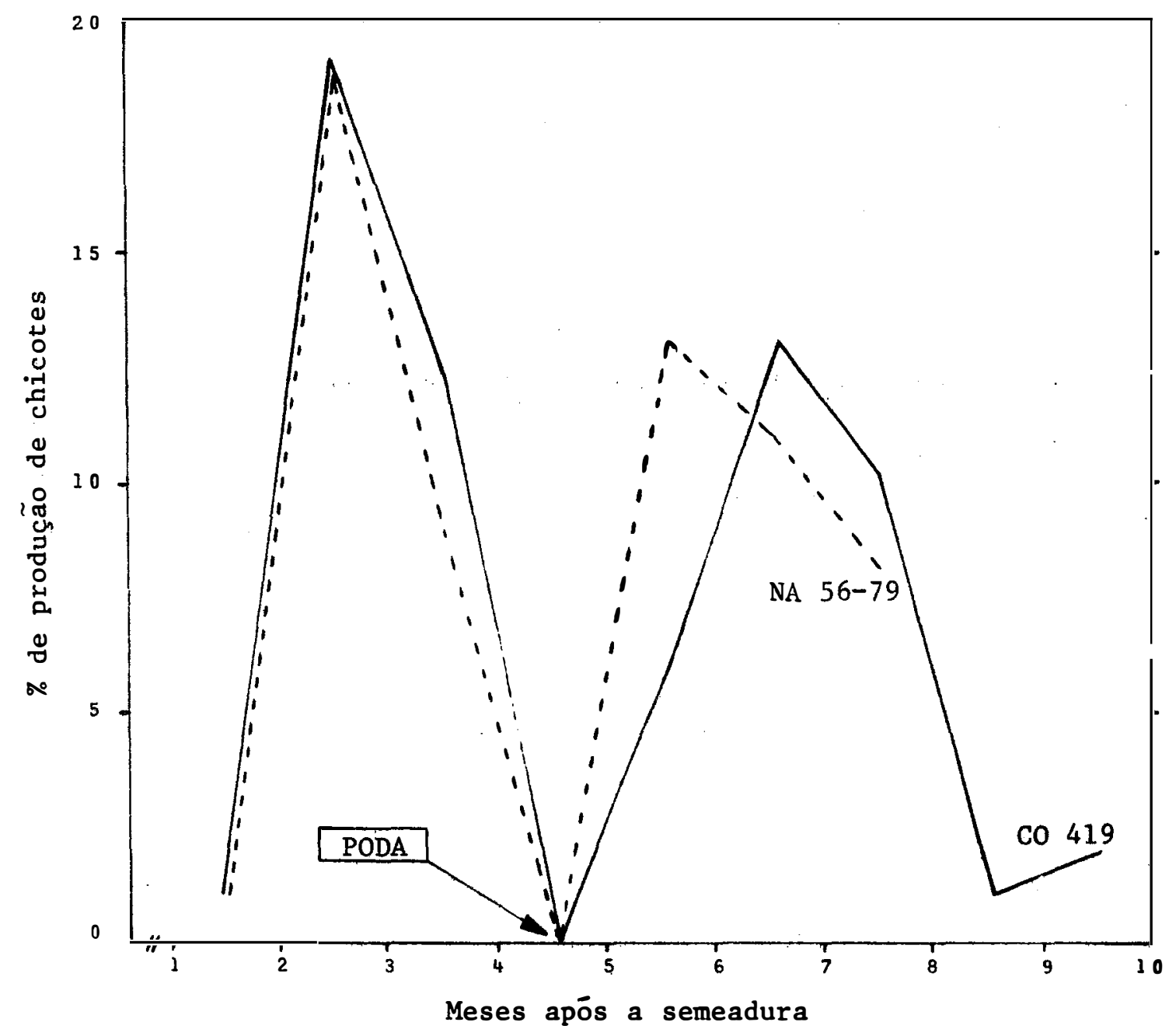

Figura 1 - Representação gráfica das percentagens mensais de produção de chicotes de Ustizago scitaminea, pelas cultivares CO 419 e NA 56-79 (lote 1). 
4.7 - Influência do Fotoperiodo na Colonização de Plāntulas por U. scitominea e na Mortalidade de Plântulas

A anälise de variância revelou que os fotoperíodos de 12 e 24 horas de 1 uz não diferiram significativamente, ao nỉvel de $5 \%$ de probabilidade, em relação à colonização de plântulas por $U$. scitominea e a mortalidade de plântulas após o transplante.

As mêdias dos dados em percentagens de plântulas colonizadas e mortas são apresentadas na Tabela 12.

Tabela 12 - Influência do fotoperíodo na colonização de plântulas por $U$. scitominea e na mortalidade de plântulas da cultivar NA 56-79 (lote 2).

\begin{tabular}{|c|c|c|}
\hline \multirow{2}{*}{$\begin{array}{l}\text { FOTOPERIODO } \\
\text { (horas de luz) }\end{array}$} & \multicolumn{2}{|c|}{$M E D I A=/(\%)$} \\
\hline & Colonização & Mortalidade \\
\hline 12 & 32,20 & 58,50 \\
\hline 24 & 32.92 & 52,75 \\
\hline C.V. (\%) & 14,30 & 11,31 \\
\hline
\end{tabular}


4.8 - Influência do Substrato e Inoculação com $U$. scitaminea na Germinação de Cariopses, Colonização e Mortalidade de Plān tulas

4.8.1 - Influência do substratc e inoculação na germinação

Na anālise de variância foram encontrados valores de F significativos, ao nive1 de $1 \%$ de probabilidade, para os fatores substratos e inoculação. Porém, a interação desses fatores não foi significativa, ao nível de $5 \%$ de probabilidade.

As médias dos dados em percentagem de germinação, e transformados em arc sen $\sqrt{\mathrm{p} / 100}$, referentes aos fatores substratos $\mathrm{e}$ inoculação, encontram-se na Tabela 13.

Tabela 13 - Influência do substrato e inoculação na germinação de cariopses da cultivar NA 56-79 (lote 2).

\begin{tabular}{|c|c|c|c|c|c|c|}
\hline \multirow{2}{*}{ SUBSTRATO } & \multicolumn{2}{|c|}{ 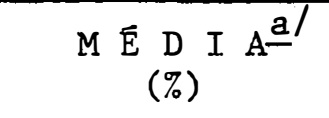 } & \multirow{2}{*}{ Média } & \multicolumn{2}{|c|}{ 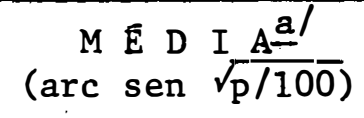 } & \multirow{2}{*}{ Média } \\
\hline & Test. & Inoc. & & Test. & Inoc. & \\
\hline Āgar-āgua & 41,17 & 33,42 & 37,30 & 39,91 & 35,30 & $37,61 \mathrm{~b}$ \\
\hline Vermiculita & 49,91 & 46,16 & 48,04 & 44,95 & 42,79 & $43,87 a$ \\
\hline Média & 45,54 & 39,79 & & $42,43 a$ & $39,05 \mathrm{~b}$ & \\
\hline
\end{tabular}

C.V. $(\%)=4,77$

a/ Proveniente de 8 repetições, cada una constituỉda por 400 cariop ses.

Obs.: Test. = Testemunha; Inoc. = Inoculada . 


\subsection{2 - Influência do substrato na colonização}

A anālise de variância acusou que os substratos āgar-água e vermiculita diferiram significativamente, ao nível de $1 \%$ de probabilidade, em relação à colonização de plāntulas por U. scitami nea.

As médias dos dados em percentagem de plântulas colo nizadas, e transformados em arc sen $\sqrt{\mathrm{p} 7 \overline{100}}$, são apresentadas na Tabela 14 .

Tabela 14 - Influência do substrato na colonização de plântulas por U. scitaminea. Cultivar NA 56-79 (lote 2).

\begin{tabular}{|c|c|c|}
\hline \multirow{2}{*}{ SUBSTRATO } & \multicolumn{2}{|c|}{$M \bar{E} D I A^{a}$} \\
\hline & $(\%)$ & $(\operatorname{arc}$ sen $\sqrt{\mathrm{p} / 100})$ \\
\hline Ảgar-āgua & 24,37 & 29,52 b \\
\hline Vermiculita & 45,00 & 42,11 a \\
\hline
\end{tabular}

C.V. $(\%)=8,05$

a/ Proveniente de 8 repetições, cada uma constituỉda por 30 plântulas.

4.8.3 - Influência do substrato e inoculação na mortalidade

A anālise de variância não acusou diferença significativa, ao nível de $5 \%$ de probabilidade, para substratos, inoculação 
e interação desses fatores.

As médias dos dados em percentagem de plântulas mortas, referentes aos fatores substratos e inoculação, encontram-se na Tabela 15 .

Tabela 15 - Influência do substrato e inoculação com U. scitaminea na mortalidade de plântulas da cultivar NA 56-79 (lote 2).

\begin{tabular}{|c|c|c|c|}
\hline \multirow{2}{*}{ SUBSTRATO } & \multicolumn{2}{|c|}{$\mathrm{M} \overline{\mathrm{E}} \mathrm{D} \mathrm{IA} \cdot \frac{a}{(\%)}$} & \multirow{2}{*}{ Média } \\
\hline & Testemunha & Inoculada & \\
\hline Āgar-āgua & 68,25 & 68,50 & 68,38 \\
\hline Vermiculita & 69,25 & 73,00 & 71,13 \\
\hline Média & 68,75 & 70,75 & \\
\hline
\end{tabular}

C.V. $(\%)=9,33$

a/ Proveniente de 8 repetições, cada uma constituída por 50 plântulas.

\section{9 - Fungos Encontrados nas Plântulas Mortas}

As percentagens de fungos encontrados nas plântulas mortas, após o transplante, referentes aos ensaios descritos em 3.6, 3.8 e 3.9.3, encontram-se na Tabela 16. Para as cariopses inoculadas desses ensaios, na Tabela 17 apresenta-se a percentagem de $U$. scitaminea em relação à dos outros fungos nas plântulas mortas. 


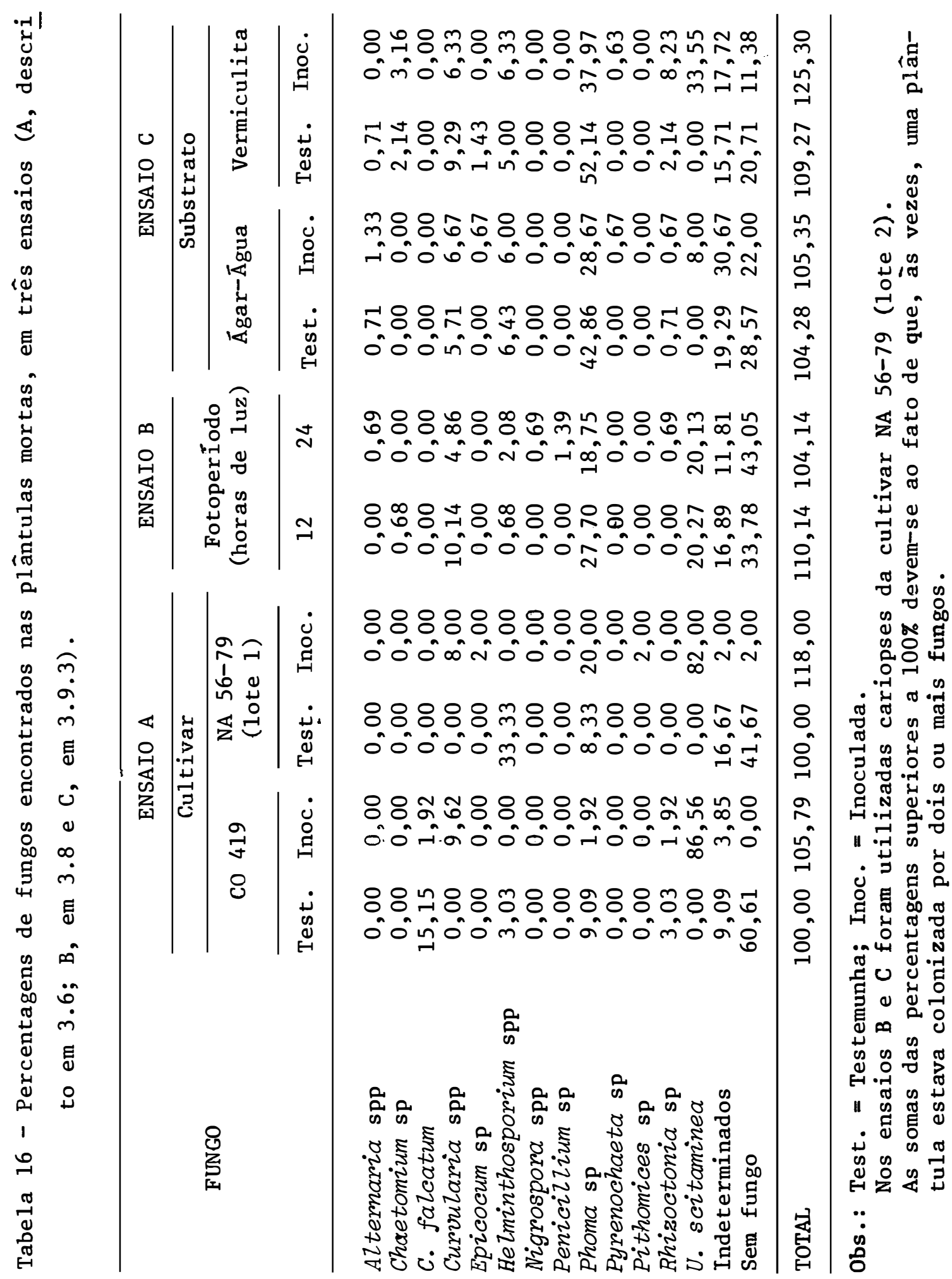


41.

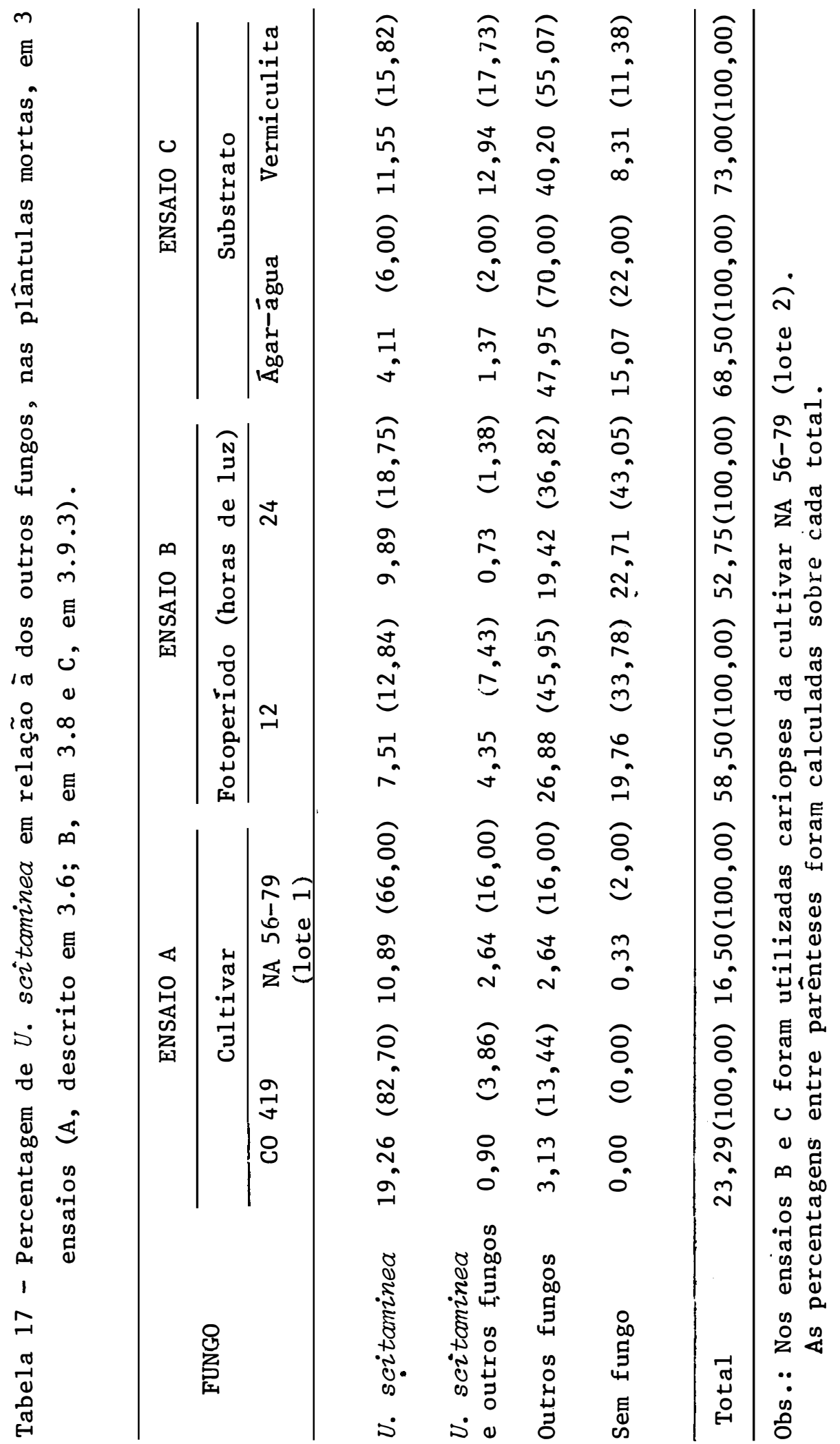


42.

5. DISCUSSÃO

5.1 - Determinação Quantitativa dos Fungos Contaminantes de Cariopses

De uma maneira geral, os gêneros de fungos patogênicos encontrados por SANGUINO (1976), SILVA (1978) e SANGUINO e TOKESHI (1980), em cariopses de cana-de-açücar, também foram observados no presente trabalho.

Entre os fungos contaminantes encontrados, destaca-se, em cariopses da cultivar CO 419, a presença do C. falcatum. Es pécies de Colletotrichum de outras gramineas são normalmente transmitidos pelas sementes (MINUSSI, 1977). Neste trabalho ficou demons trado que $C$. falcatum não foge a essa regra.

Os gêneros encontrados em percentagens mais altas fo 
ram: Curvularia $(5,25 \%)$, Colletotrichum $(10,50 \%)$ e Phoma $(13,25 \%)$, para as cultivares IAC 48/65, CO 419 e NA 56-79 (lote 2), respectivamente. De um modo geral, os gêneros de fungos patogênicos que ocor reram nas cariopses, de uma cultivar, também foram encontrados em plântulas mortas (Tabela 16), evidenciando,assim, que os mesmos são responsáveis pela morte, de grande parte,de plântulas após o transplante.

\subsection{1 - Testes de patogenicidade com C. falcatrom}

Demonstrada a patogenicidade de C. falcatron, obtido de cariopses da 'CO 419', fica evidente que este fungo se comporta como o Colletotrichum do sorgo, reforçando a teoria de que pertence a "formae speciales" de C. grominicola proposta por KIMATI (1975).

$\mathrm{Na}$ literatura năo foi encontrada nenhuma referência sobre este fungo, causando morte de plấntulas e sendo transmitido por cariopses de cana-de-açúcar. Logo, acredita-se ser este o primeiro rellato de tais ocorrências.

\section{2 - Influência do Vācuo na Germinação de Cariopses}

Com relação à germinação de cariopses (cultivar IAC 48/65), as que não foram submetidas à vácuo não diferiram estatistí camente das submetidas à vácuo de $50 \mathrm{~mm}$ de $\mathrm{Hg}$, durante dois minutos. No entanto, a germinação foi afetada pelos nỉveis de vácuo de 100 , 150 e $200 \mathrm{~mm}$ de $\mathrm{Hg}$ (Tabela 4). Provavelmente, a queda do poder ger- 
minativo das cariopses, submetidas à vácuo, foi devida às danificações mecânicas nos embriões. Resultados semelhantes foram obtidos por BLEICHER (1978) e BLEICHER e TOKESHI (1980), que utilizaram qua tro níveis de vācuo, na faixa de 250 a 550 mm de Hg. Danificaçōes re sultantes do uso do vácuo foram mencionadas por SANGUINO e TOKESHI (1976), na brotação de gemas de cana-de-açūcar, e por Ross et alii (1948), nos colmos de cevada.

5.3 - Influência do Vácuo na Colonização de Plāntulas por U. scí taminea

0 uso do väcuo de 50,150 e $250 \mathrm{~mm}$ de $\mathrm{Hg}$ não interfe riu significativamente na colonização de plântulas por U. scitconinea, para a cultivar IAC 48/65. Entretanto, observou-se uma tendência de aumentar a colonização de plântulas, por $U$. scitaminea, com o uso do vācuo (Tabela 5). BLEICHER (1978) e BLEICHER e TOKESHI (1980) ob tiveram aumento significativo na percentagem de plântulas colonizadas, oriundas de cariopses da cultivar CO 62-175 e inoculadas com vácuo de $250 \mathrm{~mm}$ de $\mathrm{Hg}$. Infelizmente, não foi possível utilizar-se, neste ensaio, esta cultivar.

5.4 - Comparação de Mētodos de Inoculação na Colonização de Plân tulas por $U$. scitaminea

As cultivares CO 419 e NA 56-79 (lote 2) não diferiram estatisticamente quanto à colonização de plântulas por U. scita 
minea. O mesmo ocorreu para os métodos de inoculação sem väcuo, com vácuo de $250 \mathrm{~mm}$ de $\mathrm{Hg}$ e por pulverização (Tabela 6). A inoculação com vácuo apresentou uma tendência de maior percentagem de plânturlas colonizadas em relação à inoculação sem vácuo, somente para a cultivar Co 419, o que também foi verificado (Tabela 5) no ensaio descrito em 3.4, para a cultivar IAC 48/65. Entretanto, a inoculação com vácuo apresentou essa mesma tendência em relação à inoculação por pulverização, para as duas cultivares.

\section{5 - Influência da Cultivar e Inoculação com U. scitcominea na Mortalidade de Plāntulas}

Quanto à mortalidade de plântulas após o transplante, as cultivares CO 419 e NA 56-79 (1ote 1) diferiram estatisticamente (Tabela 7). A cultivar NA 56-79 (lote 1) apresentou menor percentagem de plântulas mortas, o que, em parte, era esperado pela melhor qualidade das cariopses, evidenciada no teste de germinação (88:\%). Estes resultados indicam a necessidade de utilizarem-se cariopses de melhor qualidade, visando-se obter melhor eficiência no método de inoculação em cariopses com U. scitaminea.

o efeito da inoculação em cariopses com U.scitaminea sobre a mortalidade de plântulas após o transplante foi significati vo, sendo que as cariopses inoculadas apresentaram maior percentagem de plântulas mortas (Tabela 7). Este evento pode ser atribuído ao maior vigor das cariopses neste ensaio ( 1 mês de armazenamento), 
que provavelmente fez com que a mortalidade de plântulas por $U$. sc $\underline{i}$ tominea fosse mais evidenciada após o transplante. Observa-se na Tạ bela 17 que, entre as plântulas mortas, as colonizadas somente por U. scitominea constituem as maiores percentagens, ou sejam, 82,70 e $66,00 \%$, para as cultivares CO 419 e NA 56-79 (lote 1), respectivamente.

A hipótese da influência do vigor das cariopses sobre a mortalidade de plântulas inoculadas com U. scitaminea poderia ser avaliada pela germinação das cariopses inoculadas e não inocula das, porém, infelizmente, neste ensaio, não foi efetuada. Entretanto, nos ensaios descritos em 3.9.1 e 3.9.3, nos quais foi utilizada a cultivar NA 56-79 (lote 2), com nove meses de armazenamento, esta hipótese parece mais provável. Isto porque, as cariopses inoculadas e não inoculadas difèriram significativamente quanto à germinação (Tabela 13), e não diferiram significativamente quanto à mortalidade de plântulas após o transplante (Tabela 15). Supõe-se, portanto, que o vigor das cariopses pode ter influência na mortalidade de plân tulas, causada por U. scitaminea, antecipando-a ou retardando-a.

\section{6 - Relação entre a Presença de Micēlio de U. scitaminea nas Folhas e o Aparecimento de Chicotes}

Para as cultivares CO 419 e NA 56-79 (1ote 1), o tes te $\chi^{2}$ (Tabelas 8 e 9) foi significativo, ao nível de $0,1 \%$ de probabi lidade,evidenciando, assim,uma estreita relação entre a presença de micélio de $U$. scitominea nas folhas e o aparecimento de chicotes. Es 
tes resultados confirmam as observações de DUARTE (1976) e DUARTE e. TOKESHI (1978), para a cultivar PR 980. Em termos médios, aproximadamente $93 \%$ das plantas com micēlio nas folhas produziram chicotes.

Para as duas cultivares, o teste $\chi^{2}$ (Tabelas 10 e 11) foi significativo, ao nível de $0,1 \%$ de probabilidade, indicando, assim, que as plantas com micélio e sem micélio nas folhas diferiram estatisticamente quanto ao perỉodo de produção de chicotes. Em termos médios, aproximadamente $91 \%$ das plantas com micélio emitiram chí cotes precocemente (até 4 meses após a semeadura), ao passo que aproximadamente $95 \%$ das plantas sem micélio emitiram chicotes tardia mente (5-14 meses apōs a semeadura).

Embora a percentagem de plantas sem micélio nas fo1has observada neste ensaio seja, em termos médios, quase a mesma encontrada por DUARTE (1976) e DUARTE e TOKESHI (1978), a percentagem de plantas sem micêlio que produziram chicotes foi bem maior nes te ensaio. Entretanto, ressalte-se que esses autores observaram o aparecimento de chicotes somente até 100 dias após a semeadura.

o fato de não se ter detectado micélio, nas amostras dos tecidos foliares das plantas que produziram chicotes tardiamente, pode ter sido em decorrência da pequena quantidade de micélio presente nas folhas e, principalmente, à fisiologia de resistência dessas plantas retardando a colonização e esporulação.

Verifica-se na Figura 1 , que as duas cultivares apre 
sentaram praticamente a mesma distribuição quanto à produção de chí cotes. Este fato pode ser um indício da herdabilidade de resistência a U. scitominea, de origem materna, pois a cultivar co 419 è o progenitor feminino da NA 56-79. SILVA (1978) concluiu que há indicações de que o progenitor feminino tem influência na reação da pro gênie a U. scitominea. Os primeiros chicotes apareceram de 1-2 meses e as incidências máximas de 2-3 meses após a semeadura. Observa ções semelhantes foram feitas por DURAIRAJ et alii (1972).

Aproximadamente $50 \%$ da produção de chicotes ocorreu até o quarto mês após a semeadura. No períoto de 4-5 meses, as plan tas não produziram chicotes, provavelmente em decorrência da poda e posterior transplante para o campo. Embora na Figura 1 não conste, salienta-se que no período de 13-14 meses após a semeadura houve a produção de um chicote na cultivar NA 56-79 (lote 1).

Como a percentagem de produção de chicotes decresceu consideravelmente a partir do oitavo mês após a semeadura, sugere-se que, para essas cultivares, as observações sejam efetuadas até esse período.

5.7 - Influéncia do Fotoperíodo na Colonização de Plāntulas por U. scitominea e na Mortalidade de Plāntulas

Não foram observadas diferenças significativas entre os fotoperíodos de 12 e 24 horas de $1 \mathrm{uz}$, quanto à colonização de plântulas por U. scitaminea e à mortalidade de plântulas após o 
transplante, para a cultivar NA 56-79 (lote 2) (Tabela 12). Observa-se que as percentagens de plântulas colonizadas por U. scitconinea foram praticamente iguais para os dois fotoperiodos. Estes resultados foram, em parte, confirmados pela mortalidade de plântulas após o transplante deste ensaio, pois, entre elas, as percentagens de co lonizadas por U. scitaminea foram também praticamente iguais para os dois fotoperiodos (Tabela 16).

Na literatura consultada não foi encontrada nenhuma referência sobre o assunto, relacionada ao gênero Ustilago. Porém, segundo AGRIOS (1969), o fotoperíodo pode também ter efeito sobre o desenvolvimento de uma doença, primeiramente sobre a planta hospedeira. Assim, supöe-se que os fotoperíodos não exerceram influência significativa, provavelmente porque foram utilizados nos primeiros dias de vida da hospedeira ( 8 e 12 dias para a mortalidade e coloni zação de plântulas), época em que as plântulas ainda dependem das reservas das cariopses.

Os resultados obtidos demonstraram que câmaras com luz contínua podem ser usadas para as inoculações em cariopses com i. scitominea, sem perda da eficiência do método. 
5.8 - Influência do Substrato e Inoculação com $U$. scitaminea na Germinação de Cariopses, Colonização e Mortalidade de Plân tulas

5.8.1 - Influência do substrato e inoculação na germinação

Com relação à germinação de cariopses (cultivar NA 56-79, lote 2), o substrato vermiculita foi estatisticamente superior ao substrato ágar-água (Tabela 13). Observou-se que as plântulas originadas das cariopses semeadas em vermiculita apresentavam maior desenvolvimento da raiz primária do que as originadas das cariopses semeadas em ägar-água, provavelmente devido às melhores con dições de aeração e troca iônica no substrato vermiculita.

Observa-se, na Tabela 13, que a germinação das cariopses inoculadas com U. scitcominea foi estatisticamente inferior à das cariopses não inoculadas. SANGUINO e TOKESHI (1976), utilizan do a mesma concentração de esporos de $U$. scitcominea e a mesma cultí var, observaram que a inoculação reduziu a brotação de gemas. Resul tados semelhantes foram obtidos por Thren (1938), citado por LIVINGSTON (1942), LIVINGSTON (1942) e WELLS e PLATT (1949), para sementes de cevada inoculadas com Ustizago nuda. SILVA (1978) verificou que o efeito da inoculação com U. scitaminea sobre a germinação de cariopses de cana-de-açūcar dependeu da concentração de inóculo e da cultivar.

0 poder germinativo das cariopses inoculadas foi apro ximadamente $13 \%$ menor do que o das cariopses não inoculadas (Tabela 
13). Esta redução significativa pode ser, em parte, atribuída à rea ção de hipersensibilidade, ocasionando a morte do embrião ou maior número de plântulas anormais. Verificou-se que as plântulas anormais apresentavam-se bem colonizadas por U. scitcominea. Anomalias de plân tulas, originadas de cariopses inoculadas com este fungo, foram relatadas por TALBALLA (1969).

A resistência do tipo hipersensibilidade, na maioria das plantas, é controlada por um número restrito de genes e pode ser classificada como resistência vertical nos conceitos de VAN DER PLANK (1968, 1975). Como a resistência vertical tende a facilitar o aparecimento de novas raças patogênicas, a eliminação de plantas com esse tipo de resistência, através do método de inoculação em cariọp ses com U. scitaminea, pode ser vantajosa, pois se evita o surgimen to de novas raças des'se fungo. Por outro lado, a maior desvantagem deste método seria a possibilidade de reduzir o número de plantas re sistentes. Entretanto, como esse número é aparentemente pouco repre sentativo, julga-se que o erro inerente ao método é, de maneira gera1, aceitāvel, e pode ser até vantajoso. Mesmo com estas considera ções, sugere-se que estudos sejam dirigidos para a hipótese de hipersensibilidade, a fim de detectarem se, neste método, há perda de material resistente e qual a sua percentagem. 


\subsection{2 - Influência do substrato na colonização}

A colonização de plântulas por U. scitaminea foi influenciada pelos substratos utilizados, obtendo-se maior percentagem de plântulas colonizadas em vermiculita (Tabela 14). Como a maior percentagem de germinação foi verificada no substrato vermicu lita, acredita-se que a percentagem de colonização também tenha sido maior neste substrato, por ter maior número de plântulas no período em que săo mais suscetíveis a $U$. scitaminea.

Os resultados obtidos foram, em parte, confirmados no ensaio descrito em 3.9.3, pois, entre as plântulas mortas, as percentagens de colonizadas por $U$. scitaminea foram de 33,55 e 8,00\%, para os substratos vermiculita e āgar-água, respectivamente (Tabela 16). Diferença significativa entre substratos foi relatada por SILVA (1978), que obteve maior índice de doença causada por U. scitomi nea no substrato ágar-água do que no substrato solo. Logo, pode-se inferir que o substrato vermiculita é também superior a esse substrato solo, por aumentar a eficiência de seleção.

No substrato vermiculita, a percentagem de plântulas colonizadas por $U$. scitaminea foi de $45,00 \%$ (Tabela 14) neste ensaio e de $32,92 \%$ (Tabela 12 ) no ensaio descrito em 3.8 , para o mesmo fotoperíodo (24 horas de 1uz) e a mesma cultivar. Em decorrência destes resultados, foi efetuada, posteriormente, uma anālise estatística para verificar se esssa diferença seria devida ao vigor das cariopses, pois no ensaio descrito em 3.8 elas estavam com sete me- 
ses e neste com nove meses de armazenamento. Como o resultado dessa anālise foi significativo, supõe-se que a diferença nas percentagens de colonização de plântulas, desses ensaios, foi devida ao vigor das cariopses .

No substrato āgar-āgua, a percentagem de plântulas colonizadas foi de $24,37 \%$ (Tabela 14) neste ensaio, e de 18,33\% (Tâ bela 6) no ensaio descrito em 3.5, para o mesmo método de inoculação (sem vācuo) e a mesma cultivar. Esta diferença pode ser atribui da, também, ao vigor das cariopses, jā que no ensaio descrito em 3.5 ellas estavam com seis meses, e neste com nove meses de armazenamento. $\bar{E}$ provável ainda que, no ensaio descrito em 3.5, tenha havido um efeito inibitório do Tween sobre a germinação dos esporos de $U$. sci taminea, pois o mesmo foi usado sem diluição.

Por serem as cariopses de cana-de-açúcar consideradas "de vida curta" (HARRINGTON, 1972), e com base nos resultados ob tidos, recomenda-se que em trabalhos posteriores seja levado em con sideração o vigor das cariopses de cana-de-açūcar.

\subsection{3 - Influência do substrato e inoculação na mortalidade}

Quanto à mortalidade de plântulas após o transplante, não houve efeito significativo da inoculação das cariopses com $U$ 。 scitcominea (Tabela 15), o que concorda com SILVA (1978). Porẻm, enquanto não se obteve diferença significativa entre os substratos âgar-āgua e vermiculita, esse autor obteve entre āgar-āgua e solo, 
com este $\bar{u} 1$ timo apresentando menor percentagem de plântulas mortas, provavelmente devido ao efeito fungistático do solo que interferiu na germinação dos esporos de U. scitominea e dos fungos patogênicos. Comparando-se a percentagem de plântulas mortas do en saio descrito em 3.8 para o mesmo fotoperíodo, 24 horas de luz (Tabela 12) com a deste ensaio, para o substrato vermiculita e cariopses inoculadas (Tabela 15), verifica-se que ela foi maior neste ensaio. Este fato pode ser explicado pelo menor vigor das plântulas, ocasionado pelo maior tempo de armazenamento das cariopses. BYTHER e STEINER (1972) observaram maior mortalidade de plântulas de cana-de-açūcar, originadas de cariopses com um ano de idade, possive1mente devida a perda de vigor.

Além das considerações efetuadas sobre os substratos vermiculita e ágar-água, apresentadas neste item e em 5.8.1 e 5.8.2, destaca-se, ainda, que o substrato vermiculita apresentou maior facilidade na retirada das plântulas por ocasião do transplante, e ê de menor custo do que o substrato ágar-água.

\section{9 - Fungos Encontrados nas Plântulas Mortas}

Os contaminantes mais freqüentes das plântulas mortas foram Phoma sp, Curvularia spp e Helminthosporizon spp (Tabela 16). Resultados semelhantes foram obtidos por LOVELESS e SMITH (1956), BYTHER e STEINER (1969), BYTHER et alii (1971), BYTHER e STEINER (1972), KHURANA e SINGH (1972), YANG (1973), RAMALLO (1975), DUARTE (1976), SANGUINO (1976), BLEICHER (1978), DUARTE e TOKESHI 
(1978), SILVA (1978) e SANGUINO e TOKESHI (1980).

Entre as plântulas mortas da cultivar co 419 foi encontrado C. falcatum, sendo que este fungo foi também encontrado em cariopses desta cultivar. Assim, o ciclo vital deste patógeno é semelhante ao de outros Coiletotrichum de gramíneas.

Nos três ensaios de mortalidade de plântulas, a percentagem de plântulas colonizadas por fungos do gênero Phoma foi, praticamente, igual à de plântulas colonizadas por U. scitominea, sendo que essas percentagens foram maiores do que as demais (Tabela 16). Nesses ensaios (Tabela 17), observa-se que o U. scitominea ocor reu colonizando plântulas juntamente com outros patógenos, porém em percentagem menor do que à de plântulas colonizadas somente por ele. Considerando-se esses ensaios em conjunto, pode-se ve rificar que a maior percentagem de plântulas mortas após o trans. plante foi devida aos fungos contaminantes. Sendo assim, o método de inoculação em cariopses é prejudicado pela má qualidade das mesmas, em decorrência das condições de produção e contaminação com mî ¿rorganismos. Logo, para obterem-se cariopses de melhor qualidade, deve-se tentar o controle desses patógenos no campo, escolher a épo ca de colheita, e dar melhores condições de secagem e armazenamento. 
56.

\section{CONCLUSŌES}

a) 0 substrato vermiculita é melhor do que o àgar-āgua para germinação de cariopses e colonização de plântulas por $U$. scitominea.

b) 0 vácuo causa decréscimo de germinação de cariopses e tendência de acréscimo na colonização de plântulas por U. scitominea.

c) Câmaras com luz contínua podem ser usadas para inoculạções com U. scitominea, sem prejuízo para a eficiência do método.

d) A seleção de plantas resistentes a U.scitcominea, pelo método em estudo, tem inỉcio na fase de germinação, com elimina ção das plantas extremamente suscetíveis, pouco vigorosas e, possivelmente, algumas hipersensỉveis. 
e) Plantas nas quais é detectado micélio de U. scitaminea nas folhas tendem a produzir chicotes precocemente e são mais suscetiveis do que aquelas nas quais is to não ocorre.

f) A mortalidade de plântulas, após o transplante, tem como causa principal a presença de microrganismos patogênicos nas cariopses.

g) A espécie $C$. falcatum pode atacar cariopses de cana-de-açücar e apresenta ciclo vital semelhante aos Colletotrichrom de gramíneas graniferas. 
58.

\section{LITERATURA CITADA}

ABBOTT, E.V., 1938. Red Rot of Sugarcane. Technical Bulletin. United States Department of Agriculture, Washington, (641). 96 p.

AGRIOS, G.N., 1969. Plant Pathology. New York, Academic Press • 629 p.

ANTOINE, R., 1961. Smut. In: MARTIN, J.P.; E.V. ABBOTT e C.G. HUGHES. Sugar-Cane Diseases of the World. Amsterdam, Elsevier Pu b1ishing Company. v. 1, p. 327-354.

BARNETT, H.L. e B.B. HUNTER, 1972. Illustrated Genera of Imperfect.

Fungi. 3a. ed. Minneapolis, Burgess Publishing Company. 241 p.

BARTLETT, M.S., 1947. The use of transformations. Biometrics, Raleigh, 3 : 39-52.

BLEICHER, J., 1978. Efeito da Ventilação na Germinação de Cariopses e do Vācuo na Inoculação de Ustizago scitaninea, em Cana-de-Açūcar. Piracicaba, ESALQ/USP, 64 p. (Dissertação de Mestrado). 
BLEICHER, J. e H. TOKESHI, 1980. Effect of vacuum inoculation method on sugarcane caryopses colonization by Ustilago scitominea. In: Proceedings XVII Congress of the International Society of Sugar Cane Technologists, Manila. [No prelo].

BLEICHER, J. e H. TOKESHI, 1980a. Effect of sugarcane caryopses ven tilation on germination and vigor. In: Proceedings XVII Congress of the International Society of Sugar Cane Technologists, Manila. [No prelo].

BRASIL. Ministērio da Agricultura, 1976. Divisão de Sementes e Mudas. Regras para Análise de Sementes. Brasília, 188 p.

BRIEGER, F.0., 1965. Carvão de cana-de-açūcar: mal epidêmico. Brasil Açucareiro, Rio de Janeiro, 65 (2): 78-80.

BYTHER, R.S. e G.W. STEINER, 1969. Seedling diseases and their control. Annual Report. Hawaiian Sugar Planters' Association. Experiment Station, Honolulu, p. 58-59.

BYTHER, R.S. e G.W. STEINER, 1972. Four sugarcane seedling diseases in Hawaii: causal agents, control, and a selective medium for iso lation. Phytopathology, Lancaster, 62(1): 120-124.

BYTHER, R.S.; G.W. STEINER e C.A. WISMER, 1971. New sugarcane diseases reported in Hawaii. Sugarcane Pathologists' Newsletter, Queensland, (7): 18-21.

CARVALHO, R. de S., 1949. Carvão de cana. Anais da Escola Superior. de Agricultura "Luiz de Queiroz", Piracicaba, 6: 1-12. 
60.

DONELAN, A.F., 1980. Improved growth of sugar cane seedlings in soil mixtures containing coconut fibre waste. In: Proceedings XVII Con gress of the International Society of Sugar Cane Technologists, Manila. [No prelo].

DUARTE, M. de L.R., 1976. Padronização Metodológica da Inoculação de Plântulas de Cana-de-Açúcar para Seleção de Resistência a Ustizago scitaminea. Piracicaba, ESALQ/USP, 76 P. (Dissertação de Mestrado).

DUARTE, M. de L.R. e H. TOKESHI, 1978. Inoculation of sugarcane seedlings for selection of resistance to Ustilago scitcominea. In: Proceedings XVI Congress of the International Society of Sugar Cane Technologists, São Paulo, p. 383-393.'

DUARTE, M. de L.R. e H. TOKESHI, 1978a. Efeito de fungicidas sobre a germinação de esporos de Ustilago scitaminea Syd. "in vitro". Summa Phytopathologica, Piracicaba, 4: 93-100.

DURAIRAJ, V.; S. NATARAJAN e D. PADMANABHAN, 1972. Reaction of some sugarcane varieties to smut (Ustilago scitaminea Syd.). Pest Articles News Summaries, London, 18(2): 171-172.

FERREIRA, S.A.; J.C. COMSTOCK e K.K. WU, 1980. Evaluating sugarcane smut resistance. In: Proceedings XVII Congress of the International Society of Sugar Cane Technologists, Manila. [No prelo].

GIBE, J.N. e F.Y. PANOL, 1969. Sugarcane breeding in Victorias. Sugar News, Manila, 45(12): 714-718.

HARRINGTON, J.F., 1972. Seed storage and longevity. In: KOZLOWSKI, T.T. Seed Biology. New York, Academic Press. v. 3, p. 145-245. 
61.

HIRSCHHORN, E., 1949. Un nuevo metodo de infección artificial con el carbón de la caña de azúcar. Revista de Investigaciones Agrícolas, Buenos Aires, $\underline{3}(4)$ : 335-344.

KHURANA, S.M.P. e S. SINGH, 1972. Interrelationship of a fungus, Curvularia lunata with root-knot, nematode, Meloidogyne javanica in sugarcane seedling blight. Sugarcane Pathologists' Newsletter, Queens 1 and, (8): 33 .

KIMATI, H., 1975. Taxonomia, Esporulação e Patogenicidade de ColZetotrichum graminicola (Ces.) Wils. [sensu ARX, 1957]. Piracicaba, ESALQ/USP, 103 p. (Tese de Livre-Docência).

LEE-LOVICK, G., 1978. Smut of sugarcane - Ustilago scitominea. Review of Plant Pathology, London, 57(5): 181-188.

LIVINGSTON, J.E., 1942. The inheritance of resistance to Ustilago nuda. Phytopathology, Lancaster, $32(6):$ 451-466.

LOVELESS, A.R. e C.E.M. SMITH, 1956. Seedling blight of sugar-cane - a new disease caused by HeZminthosporium sacchari Butler. Annals of Applied Biology, Cambridge, 44(3): 419-424.

MANGELSDORF, A.J., 1966. Um Programa de Melhoramento da Cana-de-Açúcar para a Agroindústria Canavieira do Brasil. Rio de Janeiro, Instituto do Açúcar e do Ālcool. 63 p.

MATA, J.F. da, 1975. Preservaçāo e Determinação de Viabilidade de Clamidosporos de Ustilago scitaminea. Piracicaba, ESALQ/USP, 66 p. (Dissertação de Mestrado).

MATA, J.F. da e H. TOKESHI, 1976. Comparação entre três métodos de preservação de Ustilago scitominea. Summa Phytopathologica, Piracicaba, $\underline{2}(3): 187-193$. 
MINUSSI, E., 1977. Taxonomia e Esporulação de ColZetotrichum graminicola (Ces.) Wils. (sensu ARX, 1957) e Patogenicidade em Sorgo Sorghrom bicolor (L.) Moench. Piracicaba, ESALQ/USP, 78 p. (Tese de Doutoramento).

PLOPER, D. e N.E.V. de RAMALLO,(1979). Actividad antibiótica de ex tractos de Ustilago scitominea Sydow. 4 p. [Comunicação feita a Las Jornadas Fitosanitarias Argentinas].

POPP, W., 1958. An improved method of detecting loose-smut mycelium in whole embryos of wheat and barley. Phytopathology, Lancaster, 48(12): $641-643$.

RAMALLO, N.E.V. de, 1975. Tizón en plantines de caña de azúcar. Revista Industrial y Agrícola de Tucumān, San Miguel, 52(2): 77-81.

ROSS, J.G.; W.M. SEMENIUK; D.K. TAYLOR e B.C. JENKINS, 1948. Factors affecting the degree of infection of barley by loose smut (Ustilago nuda (Jens) Rostr.). Scientific Agriculture, Ottawa, 28(11): 481-492.

SANGUINO, A., 1976. Patologia e Controle dos Fungos de Sementes de Cana-de-Açúcar e Resistência de Progênies à Helminthosporium sacchari. Piracicaba, ESALQ/USP, 77 p. (Dissertação de Mestrado).

SANGUINO, A. e H. TOKESHI, 1976. Vácuo e Ustilago scitaminea alterando a brotação de cana-de-açúcar. Brasil Açucareiro, Rio de Ja neiro, (6): 30-35.

SANGUINO, A. e H. TOKESHI, 1980. Fungus pathology in sugarcane caryopses. In: Proceedings XVII Congress of the International Society of Sugar Cane Technologists, Manila. [No prelo]. 
SILVA, W.M. da, 1974. Produção de "Seedlings" de Cana-de-Açūcar pe 1o Beneficiamento do "Fuzz" e Transplante Precoce. Viçosa, Universidade Federal de Viçosa, 35 p. (Dissertação de Mestrado).

SILVA, W.M. da, 1978. Prē-seleção de "Seedlings" de Cana-de-Açúcar Resistentes a Ustilago scitominea, pela Inoculação das "Sementes". Piracicaba, ESALQ/USP, 65 p. (Tese de Doutoramento).

SILVA, W.M. da e H. TOKESHI, 1980. Pre-selection of Ustilago scita minea resistant sugarcane seedlings by true seed inoculation. In: Proceedings XVII Congress of the International Society of Su gar Cane Technologists, Manila. [No prelo].

TALBALLA, H.A., 1969. Smut on true seedlings of sugarcane. Plant. Disease Reporter, Washington, 53(12): 992-993.

TALBALLA, H.A. e I.A. NASR, 1974. Screening for smut resistance by true seedlings inoculation in sugarcane. Sugarcane Breeders'. Newsletter, Queensland, 34: 27-29.

TOFFANO, W.B., 1965. Resistência de variedades ao "carvão" da cana-de-açūcar ao inóculo de C.B. 45-3. O Biológico, são Paulo, 31 (3) : 65-66.

TOFFANO, W.B., 1966. Susceptibilidade de variedades de cana-de-açú car ao fungo causador do carvão (Ustilago scitominea, Sydow). Ciēncia e Cultura, São Paulo, 18(2): 126-127.

TOFFANO, W.B., 1966a. Novas observações sobre o carvão da cana-de-açūcar. O Biológico, São Paulo, 32(8): 171-178. 
TOFFANO, W.B., 1976. Estudos comparativos dos métodos de inoculação do fungo Ustilago scitaminea Syd. para fins de seleção de variedades de cana-de-açūcar. Arquivos Instituto Biológico, São Pau$10,43(1 / 2): 33-41$.

TOKESHI, H., 1979. Problemas de produção de variedades de cana-de-açúcar resistentes a Ustilago scitaminea encontrados pelo PLANALSUCAR. 13 p. Apresentado ao XII Congresso da Sociedade Brasileira de Fitopatologia, Itabuna.

TOKESHI, H., 1980. Doenças da cana-de-açūcar. In: GALLI, F.,Coord. Manual de Fitopatologia: Doenças de Plantas Cultivadas. 2a. ed. São Paulo, Editora Agronômica Ceres. v: 2, p. 141-206.

TOLEDO, F.F. de e J. MARCOS FILHO, 1977. Manual das Sementes: Tecnologia da Produção. São Paulo, Editora Agronōmica Ceres. 224 p.

TUITE, J., 1969. Plant Pathological Methods Fungi and Bacteria. Minneapolis, Burgess Publishing Company. 239. p.

VAN DER PLANK, J.E., 1968. Disease Resistance in Plants. New York, Academic Press. 206 p.

VAN DER PLANK, J.E., 1975. Principles of Plant Infection。 New York, Academic Press. 216 p.

WALLER, J.M., 1970. Sugarcane smut (Ustilago scitaminea) in Kenya. II. Infection and resistance. Transactions British Mycological. Society, London, 54 (3): 405-414.

WELLS, S.A. e A.W. PLATT, 1949. The effect of loose smut on the via bility of artificially inoculated barley seeds. Scientific Agri-. culture, Ottawa, 29(1): 45-52. 
65.

YANG, S-M., 1973. Isolation and effect of temperature on spore ger mination, radial growth, and pathogenicity of Curvularia senegalensis. Phytopathology, Lancaster, 63(12): 1541-1542. 